\title{
THESIS
}

\section{ASSESSING THE EFFECTS OF FLUVIAL ABRASION ON BONE SURFACE MODIFICATIONS USING HIGH-RESOLUTION 3-D SCANNING}

\author{
Submitted by \\ Merve Gumrukcu \\ Department of Anthropology
}

In partial fulfillment of the requirements

For the Degree of Master of Arts

Colorado State University

Fort Collins, Colorado

Spring 2017

Master's Committee:

Advisor: Michael Pante

Michelle Glantz

Michael Lacy 
Copyright by Merve Gumrukcu 2017

All Rights Reserved 


\section{ABSTRACT \\ ASSESSING THE EFFECTS OF FLUVIAL ABRASION ON BONE SURFACE MODIFICATIONS USING HIGH-RESOLUTION 3-D SCANNING}

Cut marks and carnivore tooth marks on fossil bones are important traces of the behavior and ecology of our ancestors. However, these traces are often obscured by other taphonomic processes such as fluvial abrasion. Previous studies on the effect of fluvial abrasion on cut marks suggest that sediment abrasion in fluvial environments can change the overall morphology of cut marks. Thus, analyzing the effects of fluvial abrasion on cut mark and tooth mark morphology is crucial to interpreting archaeological bone assemblages accurately. The objective of this research is to understand the effects of fluvial abrasion on cut marks and mammalian carnivore tooth marks using high-resolution 3-D data.

An experimental study was undertaken by tumbling cattle and deer bones in a rock tumbler filled with sand and water. Bones were abraded in a rock tumbler with a sand and water mixture for 152 hours. The 3-D data from cut marks and carnivore tooth marks was collected and analyzed using a white-light confocal profilometer. Qualitative macroscopic analysis shows that bone surfaces became smoother and polished after tumbling. Most cut marks and tooth marks were still visible. Results indicate that 57.1 percent of the cut marks lost their characteristic internal parallel striations and 18.4 percent of the cut marks were highly abraded and reduced to rounded indentations after tumbling. However, 65.3 percent of the cut marks preserved at least one diagnostic feature. Most of the tooth marks (78.3\%) preserved all characteristic features, such as crushed internal surfaces, high breadth: depth ratios, and U-shaped cross-sections and 100 percent 
of the tooth marks carried at least one diagnostic feature after tumbling. Only 21.7 percent of the tooth marks lost one diagnostic feature (crushed internal surface). Quantitative analysis based on the 3-D data also indicates that fluvial abrasion has a greater effect on cut marks than tooth marks. Measurements obtained from 3-D analysis of the cut marks and tooth marks show that some measurements of the micromorphology of cut marks changed significantly after tumbling, while tooth marks were not significantly altered by tumbling. Additionally, multivariate analysis using the measurements of the micromorphology allowed discrimination between cut marks and tooth marks with $100 \%$ accuracy before and after tumbling. 


\section{ACKNOWLEDGEMENTS}

First and foremost, I would convey my gratefulness to my advisor, Dr. Michael Pante, for his encouragement, guidance, and suggestions in this thesis research. I also would like to express my appreciations to the committee members, Dr. Michelle Glantz and Dr. Michael Lacy for their supports and guidance.

I am grateful to my colleagues, Trevor Keevil and Matthew Muttart, for their assistance in data collection and analysis. I am also very grateful to all my colleagues in the Department of Anthropology, Colorado State University, for their emotional support and encouragement.

I wish to thank the Ministry of National Education (Turkey) for funding and supporting me during my Master's degree.

Last but not least, I would like to express my special appreciations to my family, Ali Kemal Gümrükçü, Şefkat Gümrükçü, Gizem Şakar, Şukran Başaran, Şahver Akbıyık, and Ayşegül Olgaç, and my friends for their endless support and motivation. 


\section{DEDICATION}

To my parents, Ali Kemal Gümrükçü and Şefkat Gümrükçü... 


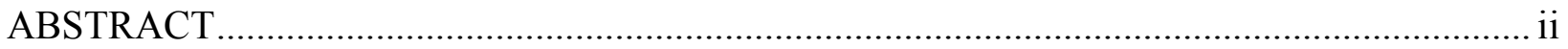

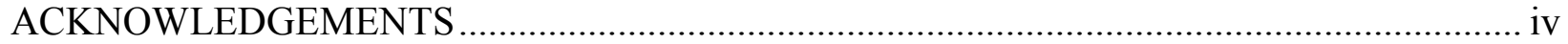

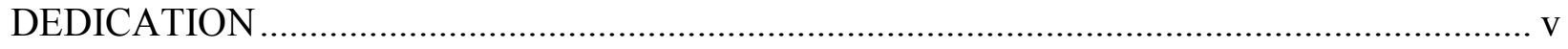

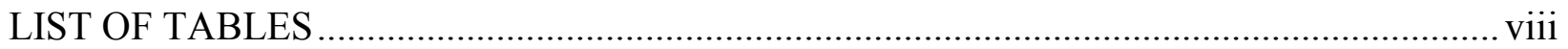

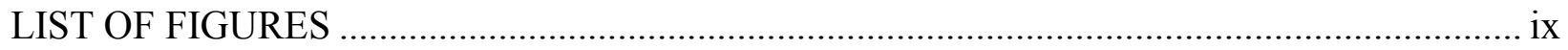

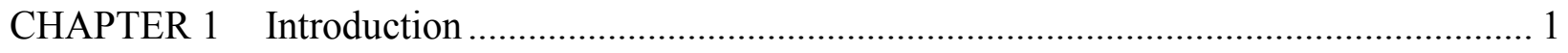

1.1 Implication of stone tool cut marks and carnivore tooth marks on fossil bones............................ 1

1.2 The importance of understanding the effects of fluvial abrasion on the bone surface

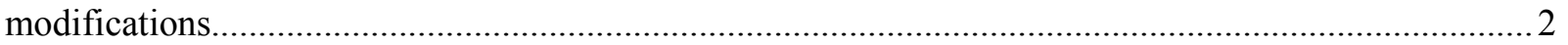

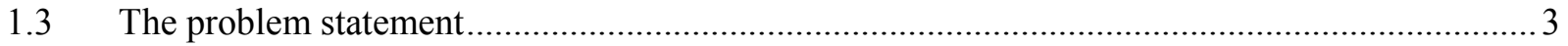

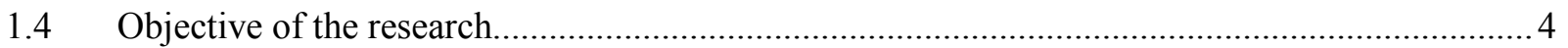

1.5 Outline of the thesis ...................................................................................................

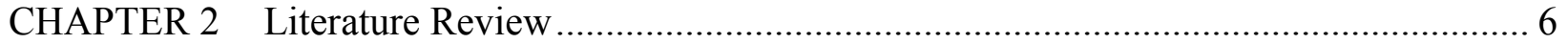

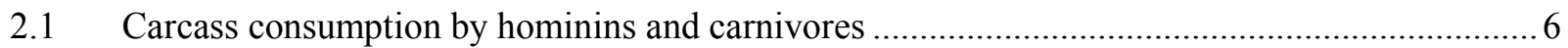

2.2 Morphology of cut marks and carnivore tooth marks ................................................................

2.3 The importance of stone tool cut marks and carnivore tooth marks ........................................... 10

2.4 The effects of fluvial abrasion on bones and cutmarks.............................................................. 12

CHAPTER 3 MATERIALS AND METHODOLOGY ………………………................... 17

$3.1 \quad$ Sample

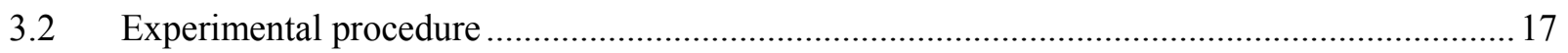

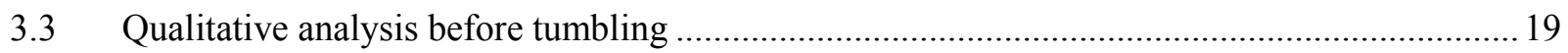

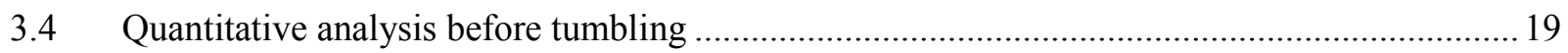

3.4.1 Scanning procedure....................................................................................... 19

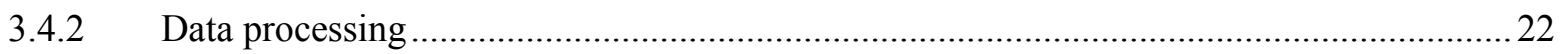

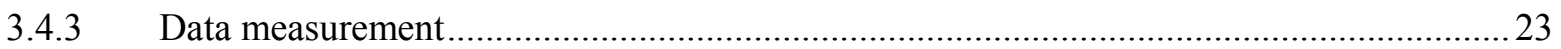

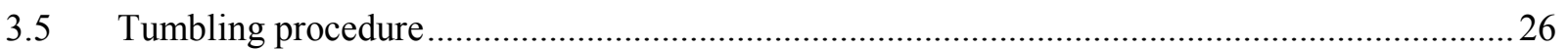

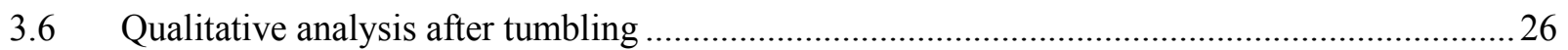

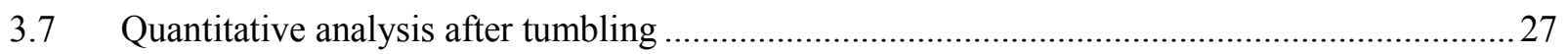

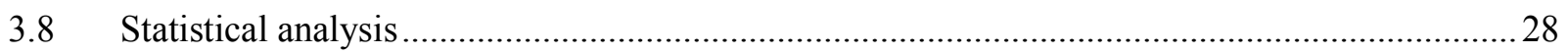

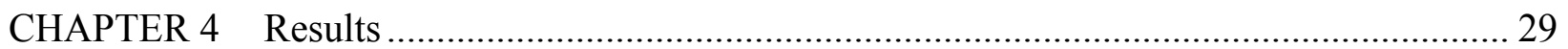

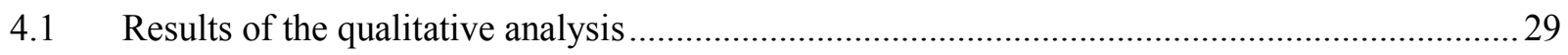


4.1.1 Changes in bone morphology from tumbling ...........................................................2 29

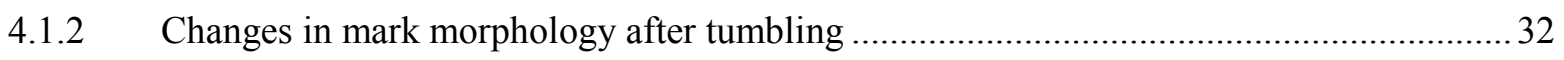

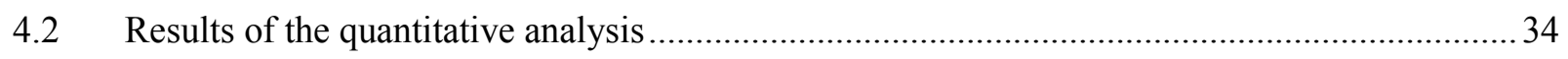

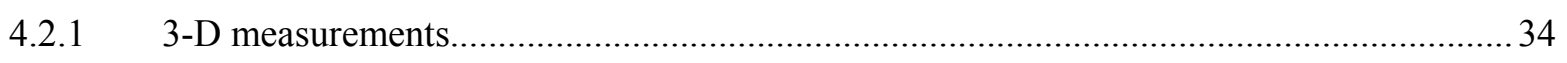

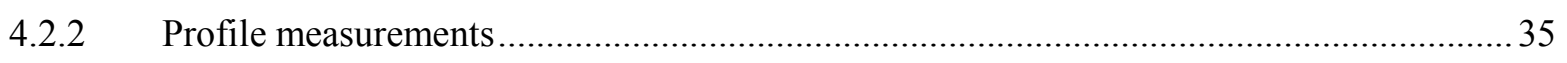

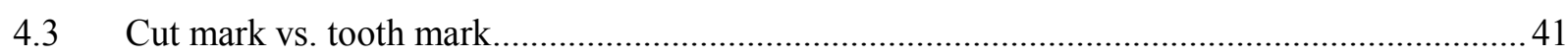

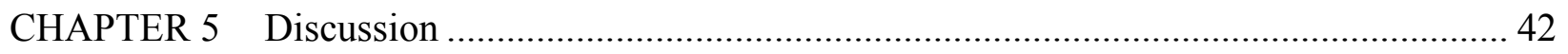

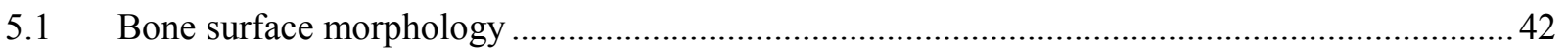

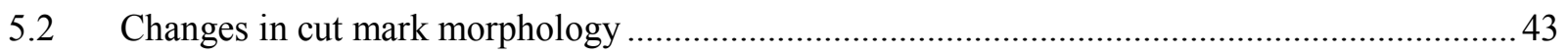

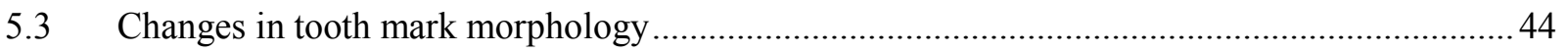

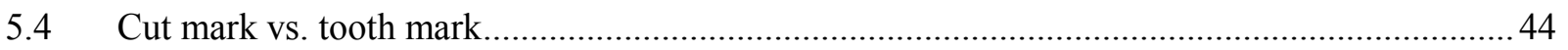

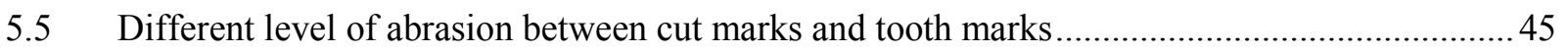

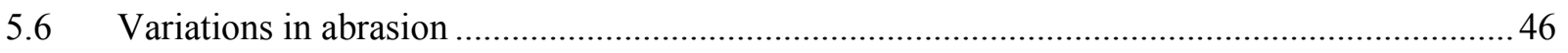

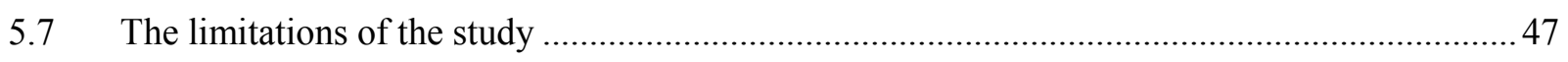

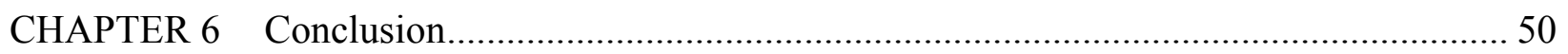

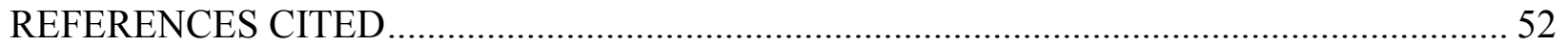




\section{LIST OF TABLES}

Table 1. List of specimens and the distribution of the cut marks and the tooth marks.

Table 2. The locations that the cross-sectional profiles were extracted from before and after

tumbling.

Table 3. The abrasion scale. 34

Table 4 . Summary statistics. Mean, median, and standard deviation of the measurements of cut marks and tooth marks before and after tumbling. $\mathrm{R}_{\mathrm{a}}$ refers to roughness. 36 Table 5. T-tests comparing the measurements of tooth and cut marks before and after tumbling. 5.a) for 3-D measurements, 5.b) for deepest profiles, 5.c) for central profiles, 5.d) for deepest profiles with extra profiles, 5.e) for central profiles with extra profiles. 39 


\section{LIST OF FIGURES}

Figure 1. "Diagram of relative grades of rounding in the large mammal bone experiment" (Fernandez-Jalvo and Andrews, 2003, p. 153)................................................................ 13

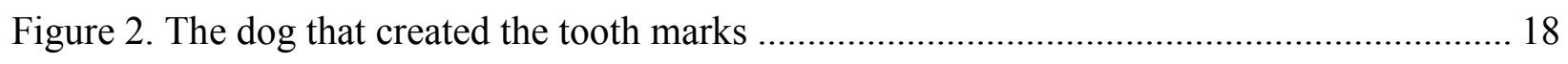

Figure 3. Nanovea ST400 white-light confocal profilometer. ............................................... 20

Figure 4. "V" shaped symbols around the cut marks and the borders of the scanned areas........ 21

Figure 5. "O" shaped symbols around the cut marks and the borders of the scanned areas........ 21

Figure 6. Two studiables from a single cut mark a) studiable formed as a result of filling missing data, b) studiable created by removing form of the bone after missing data was filled. Scales on the figures represent the relationship between color and depth in the studiables..................... 23

Figure 7. Two studiables from a single cut mark that shows 3-D data measurements based on the studiable shown in Figure $6 \mathrm{~b}$ a) studiable showing the location of the deepest point (at the center of the white circle) and measurements of maximum length and maximum width, b) studiable showing the measurements of surface area, volume, maximum depth, and mean depth. 24 Figure 8. Area of a hole from the cross-sectional profile extracted from the deepest point of a single

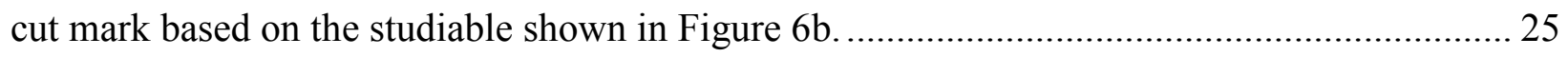
Figure 9. Highlighted part of the cross-sectional profile in Figure 8, showing opening angle and

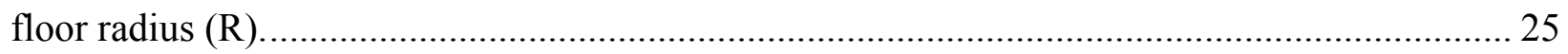

Figure 10. Locations where cross-sectional profiles were taken on extracted scanning surface of a

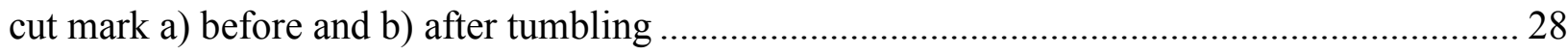

Figure 11. High level of abrasion on the epiphyses of two deer bones. a and c) before tumbling, $b$ and d) after tumbling. Highly abraded areas were shown by the arrows. 30 
Figure 12. Images of the surfaces of two different cattle bones before and after tumbling. a and c) before tumbling, b and d) after tumbling. Red arrows show the depressions and blues arrows show the straight incisions. 31

Figure 13. a) the bone surface before tumbling b) exfoliation on the bone surface after tumbling.

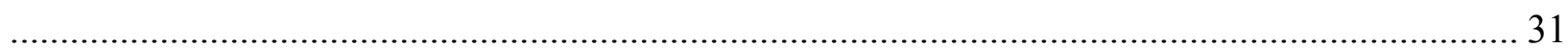

Figure 14. 3-D view of two different cut marks with shoulders, a and b) shows one cut mark before tumbling (a) and after tumbling (b), c and d) shows another cut mark before tumbling (c) and after tumbling (d). 33 Figure 15. Discriminant analysis of measurements of the cut marks and the tooth marks a) before tumbling b) after tumbling. CM represents cut mark and TM represents tooth mark. 41 


\section{CHAPTER 1}

\section{INTRODUCTION}

\subsection{Implication of stone tool cut marks and carnivore tooth marks on fossil bones}

Bone surface modifications created by different agents, such as carnivores and hominins, can provide vital information about the taphonomic history of a bone assemblage in an archaeological site (Fisher, 1995; Blumenschine et al., 1996). It is known that butchering an animal leaves marks on bones (Binford, 1981). Thus, the presence of stone tool cut marks on fossil bones is an indication of hominin access to those bones (Shipman and Rose, 1983). Hominins may have utilized several materials from animal carcasses, such as meat, marrow, bones, horns, skin and tendons, to feed themselves or make tools and clothes (Shipman and Rose, 1983). Butchering marks on bones thus offer substantial information about subsistence behavior, and social and economic structure of hominins (Fisher, 1995). Just like hominins, carnivores leave traces such as tooth marks on bones during carcass consumption (Sutcliffe, 1970; Binford, 1981; Haynes, 1980,1983; Capaldo and Blumenschine, 1994), and these traces thus indicate carnivore involvement in archaeological assemblages (Haynes, 1980; Binford, 1981; Potts and Shipman, 1981).

Stone tool cut marks and carnivore tooth marks found in archaeological faunal assemblages offer vital information about the feeding behaviors of hominins and carnivores, and their ecological interactions (Binford 1981; Blumenschine, 1988, 1995; Capaldo, 1995; Pante et al., 2012). The morphology of cut marks can provide clues about the butchery behaviors of hominins, such as skinning, disarticulation and defleshing (Binford, 1981; Noe-Nygaard, 1989; Merritt, 2012). Additionally, bone surface modifications can provide important information about the order 
of hominin and carnivore access to animal carcasses in an archaeological assemblage (Pante et al., 2012; Pante, 2013).

Assemblages that preserve evidence of hominin and carnivore feeding activities have been discovered in Early Pleistocene archaeological sites, such as Olduvai Gorge (Tanzania), Koobi Fora (Kenya), and Swartkrans Cave (South Africa) (Bunn, 1981; Potts and Shipman, 1981; Oliver, 1994; Pickering et al., 2005; Pobiner et al., 2008; Pante, 2013). Researchers have analyzed the morphology of these traces (Walker and Long, 1977; Potts and Shipman, 1981; Shipman and Rose, 1983; Blumenschine et al., 1996; Greenfield, 1999; Noe-Nygaard, 1989; Bello and Soligo, 2008; Boschin and Crezzini, 2012; Bello, 2011; Pante et al., 2017), and compared their locations and frequencies with experimentally-created feeding trace models (Blumenschine, 1988, 1995; Capaldo, 1995; Pante et al., 2012; Pante, 2013). These models were created to understand the feeding ecology of hominins and carnivores by simulating different carcass consumption scenarios based on the incidences of long bones bearing cut marks, hammerstone percussion marks, and carnivore tooth marks (Blumenschine, 1988, 1995; Capaldo, 1995; Pante et al., 2012; Pante, 2013).

The models were used to assess the relative timing of hominin and carnivore access to flesh marrow, and grease from carcasses (Pante et al., 2012), inferring the relative involvement of hominin and large carnivore activity in an archaeological bone assemblage (Blumenschine, 1995).

\subsection{The importance of understanding the effects of fluvial abrasion on the bone surface} modifications

Many archaeological sites are preserved in fluvial environments and have been affected by sediment abrasion during transport and deposition (Behrensmeyer, 1988). Therefore, fluvial abrasion is one of the natural processes that can affect morphology and frequency of bone surface modifications (Shipman and Rose, 1983, 1988; Pante, 2013). This suggests that fluvial abrasion 
has the potential to affect interpretations on the behavior and the ecology of hominin feeding (Pante et al., 2012).

Several studies have investigated the effects of sediment abrasion on bone surfaces that result from hydraulic processes (Fernandez-Jalvo and Andrews, 2003; Thompson et al., 2011; Griffith et al., 2016). These studies emphasize that the sediment abrasion rate on bones is influenced by several factors, including bone condition, proportions of sediment/water, transport modes, sediment type, sediment grain size, and sediment grain morphology. However, few studies (Shipman and Rose, 1983,1988; Gaudzinski-Windheuser et al., 2010) have been undertaken to understand the effects of fluvial abrasion on cut marks.

Shipman and Rose $(1983,1988)$ have carried out the most systematic observations of the effects of fluvial abrasion on cut mark morphology and found that cut marks are highly abraded and lose their diagnostic features after only a few hours of abrasion in a tumbler. A later study conducted by Gaudzinski-Windheuser et al. (2010) determined that cut marks are highly eroded, and can be completely eroded after only 16 hours of sediment abrasion results from hydraulic movement.

\subsection{The problem statement}

The studies mentioned above (Shipman and Rose, 1983,1988; Gaudzinski-Windheuser et al., 2010) were limited to only qualitative analysis and did not provide detailed quantitative data gathered from the cut marks. Thus, there is to date very little knowledge of the specific effects of sediment abrasion on cut mark morphology. Additionally, the effect of sediment abrasion resulting from hydraulic movement on carnivore tooth marks remains completely unknown. It is clear that further research is necessary to gain a more comprehensive understanding of the effects of fluvial processes on the morphology of both cut and tooth marks. 


\subsection{Objective of the research}

The purpose of the present research is to investigate how sediment abrasion resulting from water movement affects stone tool cut mark and carnivore tooth mark morphology and whether it is still possible to distinguish cut marks from tooth marks with a high level of accuracy after fluvial abrasion. In the present study, it is hypothesized that sediment abrasion from hydraulic processes will obscure the diagnostic features of cut marks and carnivore tooth marks by altering their micromorphology. To test this hypothesis, cut- and tooth-marked bones were abraded in a rock tumbler for 152 hours (using sand and water) and the effects of this process were observed using qualitative and quantitative criteria. Qualitative criteria are based on visual observation of rounding and polishing of the bone surfaces, and the effect of these processes on the potential identifiability of cut and tooth marks. Quantitative criteria were collected using a White-light non-contact confocal profilometer that provides high resolution 3-D data on the micromorphology of cut marks and carnivore tooth marks before and after tumbling. This study is thus a significant step to try and understand the effects of fluvial abrasion on bone surface modifications and the first to provide detailed quantitative data on the process.

\subsection{Outline of the thesis}

In the following chapters of this thesis the qualitative and quantitative results of these experiments will be presented. Chapter 2 offers the literature background related to the morphology of bone surface modifications and the effects of sediment abrasion that results from water movement on bone surfaces and bone surface modifications. Chapter 3 explains the materials and methodology used in the study. Chapter 4 presents the results obtained from the qualitative and quantitative analyses. Chapter 5 discusses the methodology used to collect and 
measure the data and the findings of the study. Lastly, in Chapter 6, conclusions based on the results of the study and suggestions for future studies are offered. 


\section{CHAPTER 2}

\section{LITERATURE REVIEW}

\subsection{Carcass consumption by hominins and carnivores}

It is widely suggested that hominins and large carnivores modified bones and left characteristic marks on bone surface during carcass consumption (Binford, 1981; Gifford, 1981; Potts and Shipman, 1981; Shipman and Rose, 1983; Blumenschine et al., 1996). Hominins consumed animal carcasses by butchering the carcass parts and removing marrow from bone using stone tools (Bunn, 1981; Blumenschine and Selvaggio, 1988; Selvaggio, 1994). Butchery is the process of segmentation of an animal carcass by humans to transport and consume it (Lyman, 1987). In removing consumable parts of an animal using stone tools, distinctive marks such as cut marks and percussion marks are left on bone (Gilbert and Richards, 2000). Carcass consumption by carnivores also produces characteristic marks on bone surfaces (Sutcliffe, 1970; Binford, 1981; Haynes, 1980,1983; Capaldo and Blumenschine, 1994). During feeding, carnivores modify bones using their teeth and leave four main kinds of tooth marks on bones; "punctures, pits, scores and furrows" (Binford, 1981, p. 44). Gnawing can cause the formation of punctures or pits, depending on the resistance of the gnawed bone portion (Binford, 1981). Scoring marks result from rubbing teeth against compact bone, sometimes resembling cut marks. Furrowing marks, the advanced stages of puncturing, are formed by repetitive jaw motion (Binford, 1981). The presence of these kinds of modifications on fossil bones led researchers to focus on the causal link between behaviors and marks (Bunn, 1981; Potts and Shipman, 1981).

Before the 1970s, faunal analyses focused mainly on prehistoric butchery methods, assuming that bone assemblages were derived only from hominin behaviors, and underestimated 
other taphonomic agents that may have contributed (Lyman, 1987). "A taphonomic agent is the source of energy or force production, such as gravity, a hominin, or a carnivore, from which taphonomic processes are generated" (Lyman, 1987, p. 254). At that time, it was widely accepted that if the archaeological assemblages could be explained by human behavior observed in ethnoarchaeological studies, hominins were the likely agent of these accumulations. Thus, the possibility that other taphonomic agents had altered the assemblages was underestimated (Lyman, 1987). In the 1970s, the importance of cause and effect in taphonomy was noticed, and the focus of taphonomic analyses "shifted from identifying the agent on the basis of inferred behaviors to first identifying the taphonomic agent and then inferring the behaviors of that agent" (Lyman, 1987, p. 258). This awareness brought along a wide range of studies on identifying the agents and the characteristic morphological features of the marks that the agents caused (Shipman and Rose, 1983).

\subsection{Morphology of cut marks and carnivore tooth marks}

Many researchers have studied the traces of carcass consumption produced by hominins and carnivores to reveal hominin feeding ecology (Binford, 1981; Brain, 1981; Bunn, 1981; Potts and Shipman, 1981; Blumenschine, 1988, 1995; Noe-Nygaard, 1989; Pante et al., 2012). Establishing characteristic features of marks is vital to be able to identify the responsible agent that created these marks and formed the archaeological assemblages (Potts and Shipman, 1981; Shipman and Rose, 1983). Diagnoses of cut marks created by hominins using stone tools can sometimes be difficult because similar marks can be generated by carnivores during carcass consumption (Potts and Shipman, 1981) or trampling by ungulates (Behrensmeyer, 1986; Dominguez-Rodrigo et al., 2009). Therefore, researchers established diagnostic features of cut marks, carnivore tooth marks and other processes to distinguish between the responsible agents of 
the marks on fossil samples (Bunn, 1981; Potts and Shipman, 1981; Shipman and Rose, 1983; Olsen and Shipman, 1988; Noe-Nygaard, 1989; Dominguez-Rodrigo et al., 2009).

Potts and Shipman (1981) undertook a study on the morphology of cut marks and carnivore tooth marks using a scanning electron microscope (SEM) to diagnose the taphonomic agents of the marks on fossils from Olduvai Gorge, Tanzania. They identified a set of morphological criteria to differentiate cut marks from carnivore tooth marks on bones (Potts and Shipman, 1981). The slicing process by stone tools produces parallel longitudinal striations within main grooves of the cut marks due to the non-uniform morphology of their cutting edges. A chopping process applied perpendicularly at the bone surface creates cut marks that have V-shaped cross-sections. Upper parts of chopping marks are usually wider than those of slicing marks, and chopping marks do not have fine parallel striations in comparison with slicing marks (Potts and Shipman, 1981). Tooth scratches display flattened bottoms and lack fine parallel striations in comparison with slicing and scraping marks, which makes differentiation of these marks possible. They claimed that magnification may be necessary to differentiate these marks because it is often difficult to distinguish small tooth scratches from slicing marks by the naked eye (Potts and Shipman, 1981).

Bunn (1981) and Shipman and Rose (1983) also identified diagnostic features of cut marks and tooth marks. Bunn (1981) points out that the grooves that form cut marks can be one or multiple, and their length can range from a couple of millimeters to a couple of centimeters. In general, the grooves are V-shaped in transverse section (Bunn, 1981). However, some cut marks have a partially flat base because cutting edges of stone tools become blunt as a result of overutilization (Bunn, 1981). Shipman and Rose (1983) specify that although slicing marks occasionally seem V-shaped in transverse section, their shape varies. They (Shipman and Rose, 
1983) observed parallel narrow striations within slicing marks and found a great number of shoulder effects in their study.

Carnivore tooth marks are usually discernable from cut marks with the unaided eye because they are often wider than cut marks and have U-shaped cross-sections (Bunn, 1981). Tooth scratches are also more irregular in trajectory than slicing marks (Shipman and Rose, 1983). Since the information that stone tool cut marks and carnivore tooth marks can provide is significant to understand hominin feeding ecology (Binford, 1981; Potts and Shipman, 1981; Blumenschine, 1988, 1995; Fisher, 1995; Pante et al., 2012), these researchers aimed to be able to identify and distinguish the marks on fossil bones by conducting these detailed studies.

Blumenschine et al. (1996) state that it is possible to identify the agents of bone modification with the high level of accuracy (99\%) based on the diagnostic features of cut marks and tooth marks (e.g. low breadth:depth ratio for cut marks, high breadth:depth ratio and crushing in the internal surface for tooth marks) using only a hand lens and low-power light microscope. However, the level of accuracy in detecting the agent of bone modification at a macro scale depends on the level of expertise of researchers and this remains unassessed for most researchers (Pante et al., 2017). Further, Pante et al. (2017, p. 8) claim that "the accuracy of individual identifications is impossible to evaluate with these traditional methods."

Recent studies have used technologies capable of capturing 3-D data from bone surface modifications to examine the micromorphology of cut marks and tooth marks (Bello and Soligo, 2008; Boschin and Crezzini, 2012; Pante et al., 2017). Bello and Soligo (2008) pioneered this work by using an Alicona 3D Infinite-Focus imaging microscope to capture the micromorphology of cut marks. This technology allows for the collection of quantitative data from cut marks including cross-sectional form, the sharpness and depth (Bello and Soligo, 2008). A subsequent study was 
conducted by Boschin and Crezzini (2012) using a Hirox Digital Microscope KH-7700 measured depth, breadth and angles of cut marks.

Most recently, a study undertaken by Pante et al. (2017) attempted to standardize how 3-D data is collected from bone surface modifications. Pante et al. (2017) were the first to measure both cut marks and tooth marks using surface area, volume, depth, width, length, roughness, angle, and floor radius of the marks. They found the method used was able to discriminate between stone tool cut marks and carnivore tooth marks with a high level of accuracy (97.5\%) (Pante et al., 2017). This study is the foundation for all the research presented here as both the method and equipment employed are identical.

\subsection{The importance of stone tool cut marks and carnivore tooth marks}

The morphology and placement of cut marks are used to identify different butchery activities of carcass processing by hominins (Binford, 1981; Noe-Nygaard, 1989; Merritt, 2012) such as skinning, disarticulation and defleshing (Merritt, 2012). Merritt (2012) undertook an experimental study and measured some morphological features of the cut marks (width and depth) using a binocular microscope at 32x magnification. Merritt (2012) claims that cut marks produced by skinning and disarticulation are wider and deeper than those created by defleshing activity. Cut marks result from skinning activity are mostly located on lower legs and head (Binford, 1981), while dismembering cut marks are generally present at the joint surfaces of bones (Noe-Nygaard, 1989). Filleting is defined as the process of removing a large amount of meat from bone (Binford, 1981) and creates several shallow parallel cut marks (Noe-Nygaard, 1989). Filleting marks are mostly found on the neck of the bones (the area between epiphysis and shaft) since removing meat from irregular surfaces of bones is difficult (Binford, 1981). Since marrow removal results in a different type of mark (percussion mark) (Blumenschine and Selvaggio, 1988; Selvaggio, 1994), 
this activity will not be explained here. As a conclusion, morphology and placement of cut marks on bone surfaces are important to reveal butchering behavior of hominins (Noe-Nygaard, 1989).

In addition to carcass processing behaviors of hominins, the relative timing of hominin and carnivore carcass consumption can be inferred from bone surface modifications (Blumenschine, 1995, 1988; Capaldo, 1995; Selvaggio, 1998; Pante et al., 2012; Pante, 2013). However, these inferences rely on the frequency and location of bone surface modifications rather than the morphology of the marks themselves. Statistical feeding trace models that simulate different feeding scenarios were developed by Blumenschine (1988, 1995), Capaldo (1995), Selvaggio (1998), and Pante et al. (2012). These models rely on variations in the proportions of cut-, tooth-, and percussion-marked long bones in assemblages of modern bones (Blumenschine, 1988, 1995; Capaldo, 1995; Selvaggio, 1998; Pante et al., 2012; Pante, 2013). They offer different orders for hominin and carnivore access to carcasses and allow researchers to make inferences about hominin feeding interactions with large carnivores from fossil bone assemblages. These models have been applied to interpreting bone assemblages discovered in archaeological sites within Olduvai Gorge (Tanzania) to identify hominin feeding ecology in these sites (Blumenschine, 1995; Selvaggio, 1998; Pante et al., 2012; Pante, 2013). They found that the bone surface modification data obtained from the assemblages in the FLK (Zinjanthropus site), Olduvai Gorge, Tanzania, is consistent with a carnivore-to-hominin-to-carnivore model of site formation, suggesting that hominins at this site had secondary access to carcasses (Selvaggio, 1998; Pante et al., 2012). Pante (2013) points out that data from the JK2 site at Olduvai Gorge indicates that there might be multiple occupations at this sites and carnivores and hominins could have access to flesh and marrow during different occupations. Hominins could have early access to carcasses during one occupation while carnivores had sole access to carcasses during another occupation (Pante, 2013). 
Pante and Blumenschine (2010) undertook an experimental study to find out whether the incidences of cut-, tooth-, and percussion-marked long bones change when the bones are transported by flowing water. It was mentioned before that incidences of long bones bearing these marks has been used to reveal the sequence of hominin and carnivore access to animal carcasses (Blumenschine, 1995, 1988; Capaldo, 1995; Selvaggio, 1998; Pante et al., 2012; Pante, 2013). The authors (Pante and Blumenschine, 2010) used a flume with low maximum flow velocity $(50 \mathrm{~cm} / \mathrm{s})$. The flume was filled with water but not sediment. The findings of the experiment indicated that hydraulic transport did not have an important influence on the proportions of cut-, tooth-, or percussion-marked bones. Therefore, they (Pante and Blumenschine, 2010) state that the method based on the incidences of long bones bearing cut, tooth, and percussion marks can be still used to uncover the relative timing of hominin and carnivore carcass consumption for fossil assemblages deposited in low-energy fluvial environments.

\subsection{The effects of fluvial abrasion on bones and cutmarks}

Bones in fluvial channels are exposed to sediment abrasion during hydraulic transport (Shipman and Rose, 1988). Thus, abrasion observed on a bone's surface may indicate hydraulic transport of bones in an assemblage (Fernandez-Jalvo and Andrews, 2003). The likely variables that can affect the sedimentary abrasion rate on bones in fluvial environments were examined by several researchers using an SEM or a ESEM (environmental scanning electron microscope) (Shipman and Rose, 1988; Fernandez-Jalvo and Andrews, 2003; Thompson et al., 2011).

Fernandez-Jalvo and Andrews (2003) conducted an experimental study to understand the influence of sediment type and bone condition on the abrasion rate of large mammal bones. They tumbled different types of bone (fresh, dry, very weathered and fossil bones) with various sediment types (gravels, coarse sands, fine sands plus silts and clay plus silt with water) for a total of 360 
hours. The authors assessed the level of rounding and created grades "based on comparative criteria between bones of this experiment" (Fernandez-Jalvo and Andrews, 2003, p. 152). Therefore, these grades should not be thought of as the particular phases of abrasion (Figure 1). The authors observed that gravel was the most erosive sediment type for all types of bones and fresh bones showed more rounding than dry bones after tumbling with coarse or fine sands (Fernandez-Jalvo and Andrews, 2003). Additionally, clay and silts caused more rounding on fossilized and weathered bones than coarse or fine sands while fresh bones were barely abraded by clay and silts (Figure 1). Consequently, this study suggests that sediment type and bone condition have a significant effect on the abrasion level on large mammal bones (Fernandez-Jalvo and Andrews, 2003).

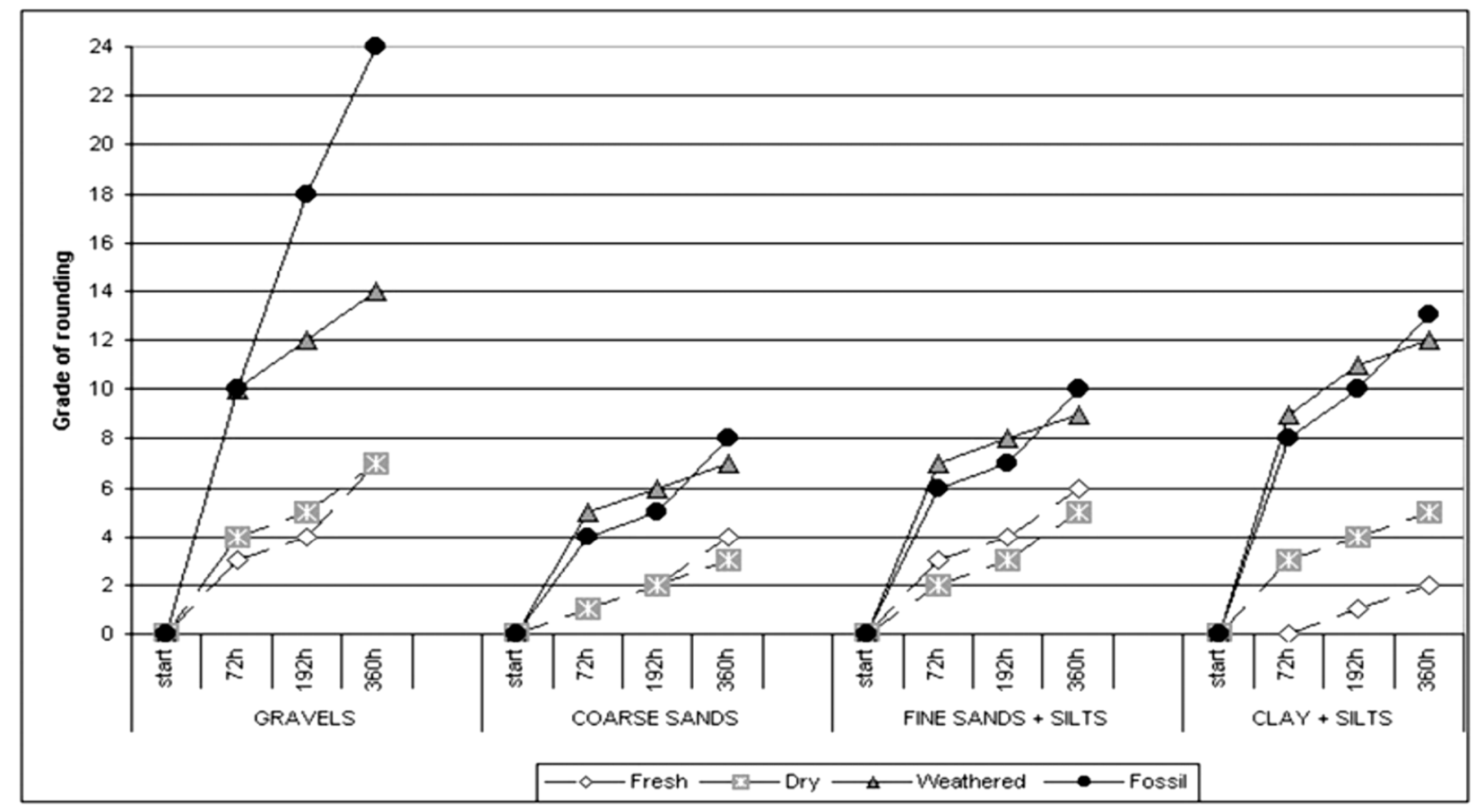

Figure 1. "Diagram of relative grades of rounding in the large mammal bone experiment" (Fernandez-Jalvo and Andrews, 2003, p. 153).

Thompson et al. (2011) undertook another study that examined the possible factors that could affect the level of abrasion on bone surfaces. They investigated the influence of different 
transport modes (bedload, saltation, suspension) and bone types (fresh, weathered, archaeological and fossilized) on the level of wear on bones (Thompson et al., 2011). The authors stated that fresh bones experienced the highest wear during saltation, while transport as bedload caused the maximum wear on archaeological (dry) bones. Additionally, weathered bones had the highest wear during transport as bedload while fossilized bones had the highest wear during suspension (Thompson et al., 2011). Therefore, this study shows that that the level of wear could be dependent on sediment transport mode and bone type (Thompson et al., 2011).

A recent study was conducted by Griffith et al. (2016) to investigate the effects of size and morphology of sediment grains, and duration of abrasion on the abrasion rate of fresh sheep bones in an annular flume for a total of 120 hours. They used silt, sand, and gravel (seven different grain size classes) and identified grain sphericity of the sediments. Results of the study show that grain size, grain sphericity, and duration of abrasion have a significant influence on the abrasion rate and greater sediment grains caused higher abrasion rate (Griffith et al., 2016). A negative correlation was found between abrasion rate and grain sphericity when data from all sediment types are included in the analysis, indicating that more angular grains caused higher abrasion rates. Also, a positive relationship was observed between duration of abrasion and the abrasion rate (Griffith et al., 2016). Based on the findings of this study (Griffith et al., 2016), it is possible to suggest that sediment grain size, sediment grain morphology, and duration of abrasion are important factors that can affect the abrasion rate of fresh mammal bones.

Gaudzinski-Windheuser et al. (2010) carried out an experimental study and examined the effects of sediment abrasion resulted from unidirectional and multidirectional water movements on bone and cut marks. The authors (Gaudzinski-Windheuser et al., 2010) utilized a stereo light microscope and 3-D surface scans to observe damage on bone and cut marks. For both water 
motions, bone morphology was important for abrasion degree on bones. During tumbling, cattle bones were abraded faster than sheep bones, and cut marks on the cattle bones nearly vanished while the cut marks on the sheep bones were still visible (Gaudzinski-Windheuser et al., 2010). The presence of periosteum played a significant role in the abrasion rate for both types of water movement, likely because it acted as a shield of the bone surface. After removal of the periosteum, the abrasion was accelerated on the bones. In unidirectional tumbling, increases in the amount of water in the tumbler resulted in a decrease in abrasion rate. For multidirectional tumbling, abrasion rate was affected by the presence of water but not by the amount (Gaudzinski-Windheuser et al., 2010). Multidirectional movement produced faster abrasion on bones than the unidirectional motion. This study based on qualitative analysis presented that most cut marks on cattle bones were altered (mostly broadened) or completely eroded after 3 to 6 hours of unidirectional and multidirectional tumbling. After 16 hours of multidirectional tumbling, the cut marks on sheep bones were altered and most cut marks on cattle bones were obliterated (Gaudzinski-Windheuser et al., 2010). This experimental study (Gaudzinski-Windheuser et al., 2010) demonstrates that sediment abrasion from water movement has the potential to alter or erase cut marks on bone surfaces.

Shipman and Rose $(1983,1988)$ carried out another experimental study using SEM to reveal the probable effects of fluvial abrasion on both bone surfaces and stone tool cut marks. They used bone from small mammals and different types of sediment for tumbling, but did not include water for all tumbling experiments. Shipman and Rose $(1983,1988)$ used $700 \mathrm{ml}$ of water and 300 $\mathrm{ml}$ of poorly sorted sand with bones that had cut marks. Shipman and Rose (1988) stated that apparent abrasion was observed on most bones after 35 hours of tumbling. It was also observed that grain size and the composition of sediments also affected the abrasion rate of the bones 
(Shipman and Rose, 1988). Sediments that had the smaller particle size such as ash and loess caused faster bone abrasion when other conditions are the same, indicating that the composition of the sediment plays an important role in the speed and amount of abrasion. Further, the authors observed that all determinative microscopic characteristics of the cut marks such as fine striations vanished after five hours of tumbling and only some remaining rounded hollows could be observed after 80 hours of tumbling (Shipman and Rose, 1983, 1988). Therefore, based on the results of qualitative analyses the authors claim that "hydraulically transported bones cannot be expected to show cut marks that can be identified on the basis of SEM inspection" (Shipman and Rose, 1988, p. 320). 


\section{CHAPTER 3}

\section{MATERIALS AND METHODOLOGY}

The objective of this research is to understand the effects of fluvial abrasion on cut marks and carnivore tooth marks using a technology that collects high-resolution 3-D data from bone surface modifications.

\subsection{Sample}

This research used limb bone fragments from six adult cattle and five sub-adult deer with unfused epiphyses. The cattle bones came from a local market, and the deer bones were received from the Paleoanthropology and Zooarchaeology Laboratory at Colorado State University, Fort Collins, Colorado. The bones (three tibiae and three femora) in the cattle sample were previously frozen with a small amount of flesh and grease remaining, while the bones from the deer sample (two tibiae and three femora) were partially weathered.

\subsection{Experimental procedure}

The condition of bones was observed and recorded prior to any experiments. Among the criteria recorded were the weathering stages of the bones as defined by Behrensmeyer (1978) and whether the bones carried periosteum and soft tissue. The cattle bones from the local market were all determined to be weathering Stage 0 or fresh. However, the deer bones were in variable states of weathering. Three deer bones indicate weathering Stage 1 while two shows Stage 0.

Once the condition of bones was recorded cut and tooth marks were inflicted on bone surfaces. Cut marks were created by slicing defleshed bones with chert and/or obsidian flakes in a direction perpendicular to the long axis of the bone. Unretouched flakes made from chert and obsidian were selected for creating cut marks because it has been suggested that cut marks 
produced by stone tools have different morphological features from those created by metal knife or blade (Bello and Soligo, 2008; Boschin and Crezzini, 2012). All cut marks were produced on degreased bone surfaces with the periosteum removed. Tooth marks were created by a large dog (2). 53 cut marks and 26 tooth marks were created. However, due to issues with sand particles getting stuck in the marks, three cut marks and three tooth marks were not scanned after tumbling and these marks were excluded from qualitative and quantitative analyses. Also, one cut mark was excluded from quantitative analysis since it was completely eroded after tumbling. Consequently, 49 cut marks and 23 tooth marks were used for both qualitative and quantitative analyses (Table 1). All marks were labeled on bone surfaces, and they were photographed and scanned following the below procedure prior to any additional modification.

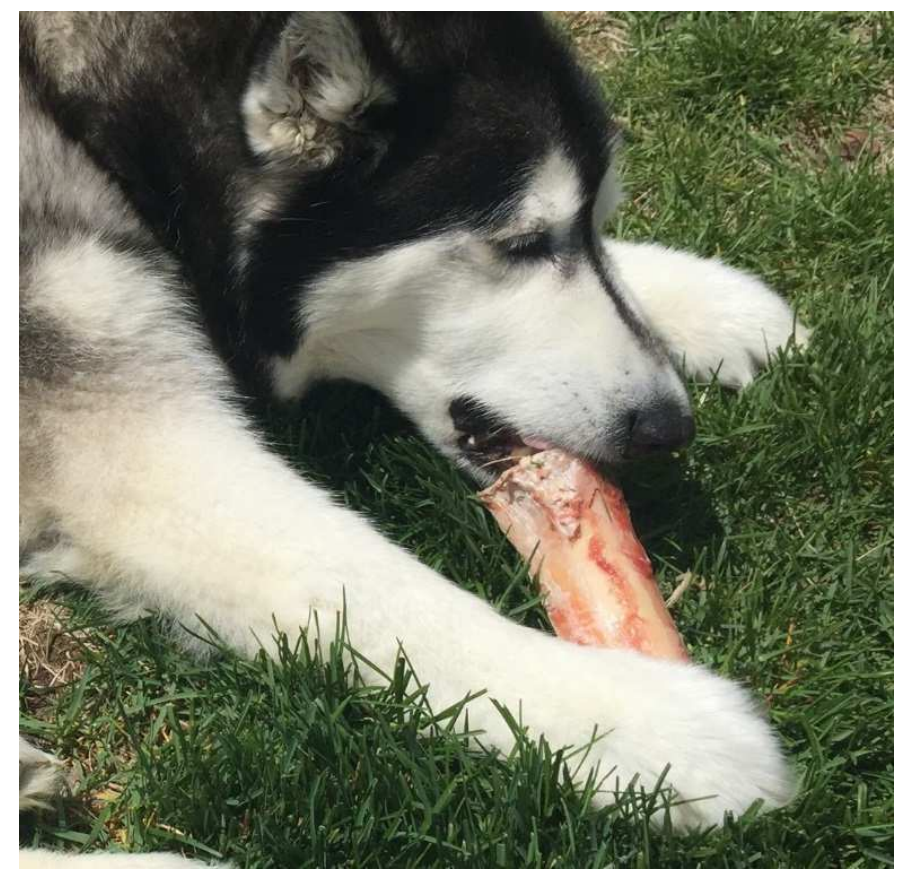

Figure 2. The dog that created the tooth marks 
Table 1. List of specimens and the distribution of the cut marks and the tooth marks

\begin{tabular}{|c|c|c|c|c|c|}
\hline Specimen & Animal & $\begin{array}{c}\text { Weathering } \\
\text { Stage }\end{array}$ & Type of Bone & $\begin{array}{c}\text { The number } \\
\text { of CM }\end{array}$ & $\begin{array}{c}\text { The number } \\
\text { of TM }\end{array}$ \\
\hline B1 & Cattle & 0 & Tibia & 1 & 4 \\
\hline B2 & Cattle & 0 & Tibia & 2 & 10 \\
\hline B3 & Cattle & 0 & Tibia & 9 & 0 \\
\hline B4 & Cattle & 0 & Femur & 3 & 4 \\
\hline B5 & Cattle & 0 & Femur & 2 & 5 \\
\hline B6 & Cattle & 0 & Femur & 5 & 0 \\
\hline B7 & Deer & 1 & Femur & 3 & 0 \\
\hline B8 & Deer & 1 & Tibia & 7 & 0 \\
\hline B9 & Deer & 0 & Femur & 7 & 0 \\
\hline B10 & Deer & 0 & Femur & 2 & 0 \\
\hline B11 & Deer & 1 & Tibia & 8 & 0 \\
\hline & \multicolumn{5}{r}{ Total } \\
\hline
\end{tabular}

\subsection{Qualitative analysis before tumbling}

Before the tumbling procedure, morphological features of all cut marks and carnivore toothmarks were examined and compared with the morphological criteria presented by Potts and Shipman (1981), Shipman and Rose (1983) and Blumenschine et al. (1996) for identifying the marks. It was observed that the cut marks and tooth marks carried almost all diagnostic features before tumbling, such as $\mathrm{V}$-shape cross section, low breath: depth ratio, and internal striations for cut marks and U-shaped cross section, high breadth: depth ratio, and crushed internal surface for tooth marks. Then, all specimens were photographed to compare with results after tumbling.

\subsection{Quantitative analysis before tumbling}

\subsubsection{Scanning procedure}

3-D reconstructions of cut marks and tooth marks were created using a Nanovea ST400 white-light non-contact confocal profilometer (Figure 3). The profilometer has a 3-mm optical pen that has a resolution of $40 \mathrm{~nm}$ on the $\mathrm{z}$-axis and can collect 3 -D data from an area as wide as 150 $\mathrm{mm} \times 150 \mathrm{~mm}$ in width and $20 \mathrm{~mm}$ in depth (Pante et al., 2017). Once 3-D reconstructions were created they were analyzed using Digital Surf's Mountains ${ }^{\circledR}$ software. 


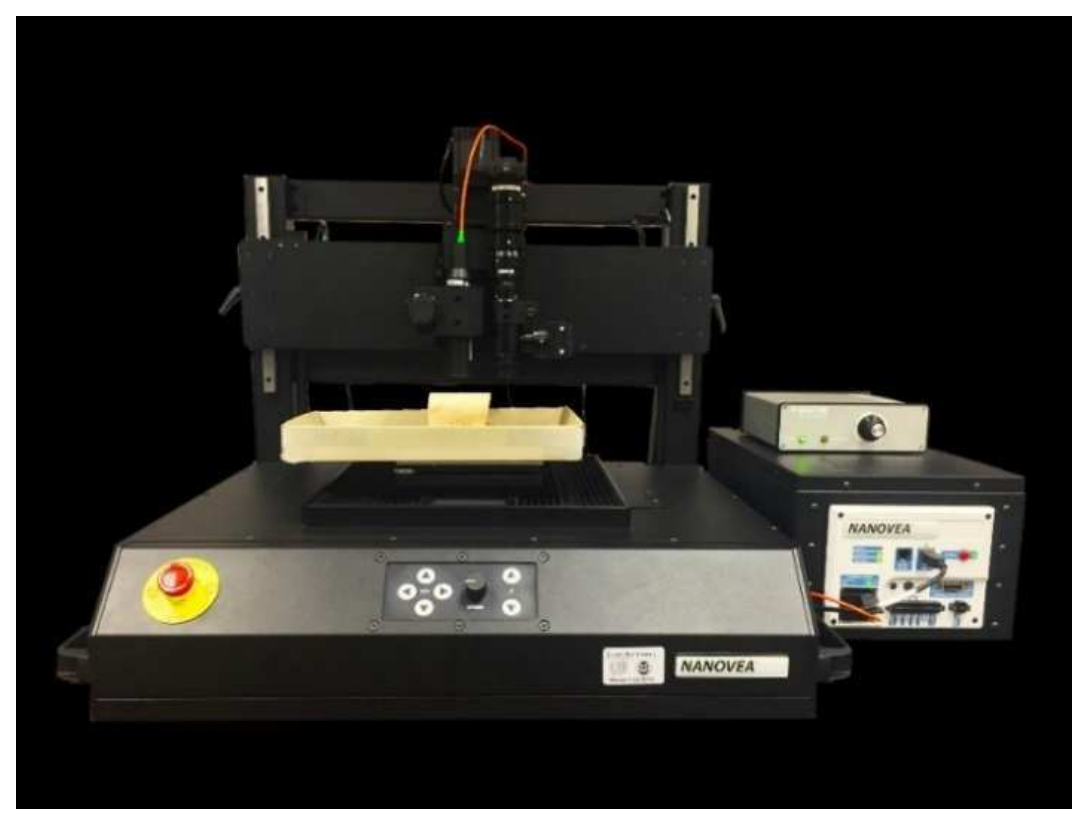

Figure 3. Nanovea ST400 white-light confocal profilometer.

The 3-D reconstructions of cut and tooth marks were created following the procedures outlined by Pante et al. (2017). Bones were placed on the platform so that marks were flat in both the $\mathrm{x}$ - and $\mathrm{y}$ - axes. The long axis of the mark was directed perpendicular to the direction of movement of the optical pen to collect cross-section profiles along the marks. Many marks were not completely straight and in these cases, the marks were placed on the platform in a way that the longest section of the mark was directly perpendicular to the orientation of the optical pen movement (x-axis). In two cases, multiple tooth marks were scanned together due to their proximity and contact with one another. While processing the data of these marks, they were separated from each other using a function of the software.

After the bones were placed on the platform, areas desired for scanning were chosen using a video microscope. To process and calculate the 3-D data accurately, a large, unmodified area around the marks was included in each scan, as prescribed by Pante et al. (2017). Markers were inscribed around modifications in order to allow the same area of a bone's surface to be selected 
in scans taken before and after they were abraded in the tumbler. Using a knife or Dremel, one symbol was created at a bottom corner of a mark and the other at a top corner (Figure 4 and Figure 5). These points are easily selected using the video microscope to highlight an area for scanning and ensured that data was collected from the same location of a bone's surface. Bones were scanned at an x resolution of $5 \mu \mathrm{m}$ and y of $10 \mu \mathrm{m}$. The frequency was set to $300 \mathrm{~Hz}$ and $1000 \mathrm{~Hz}$.

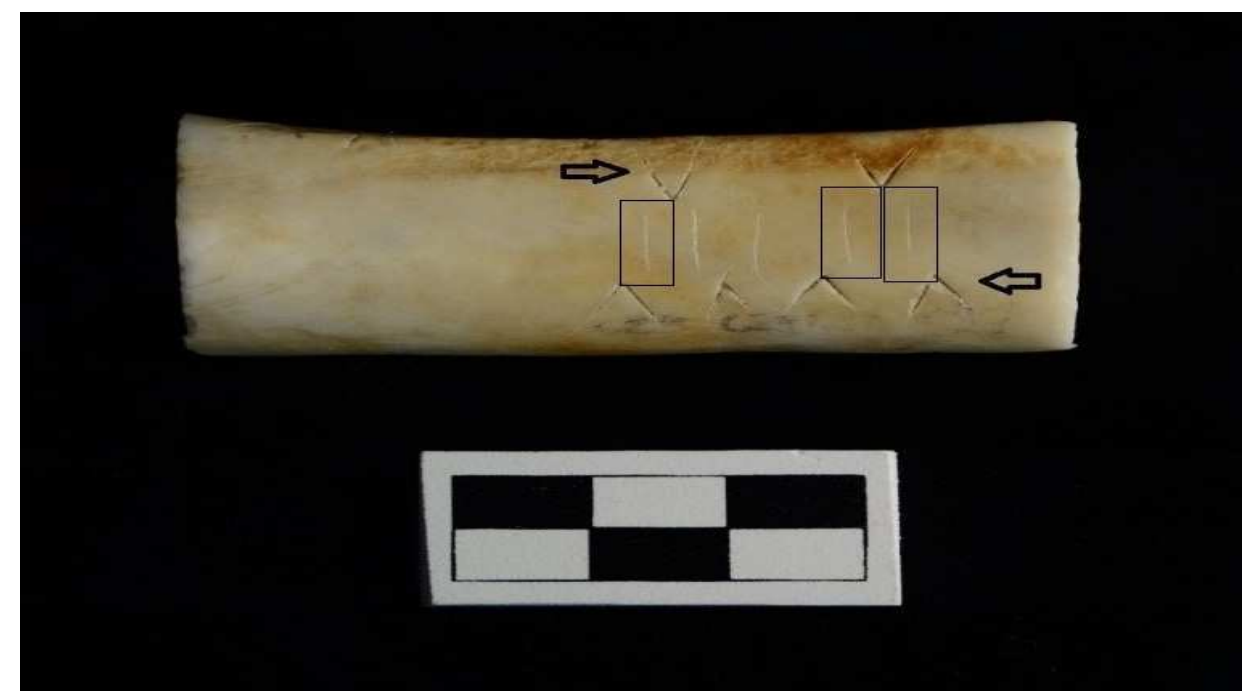

Figure 4. "V" shaped symbols around the cut marks and the borders of the scanned areas.

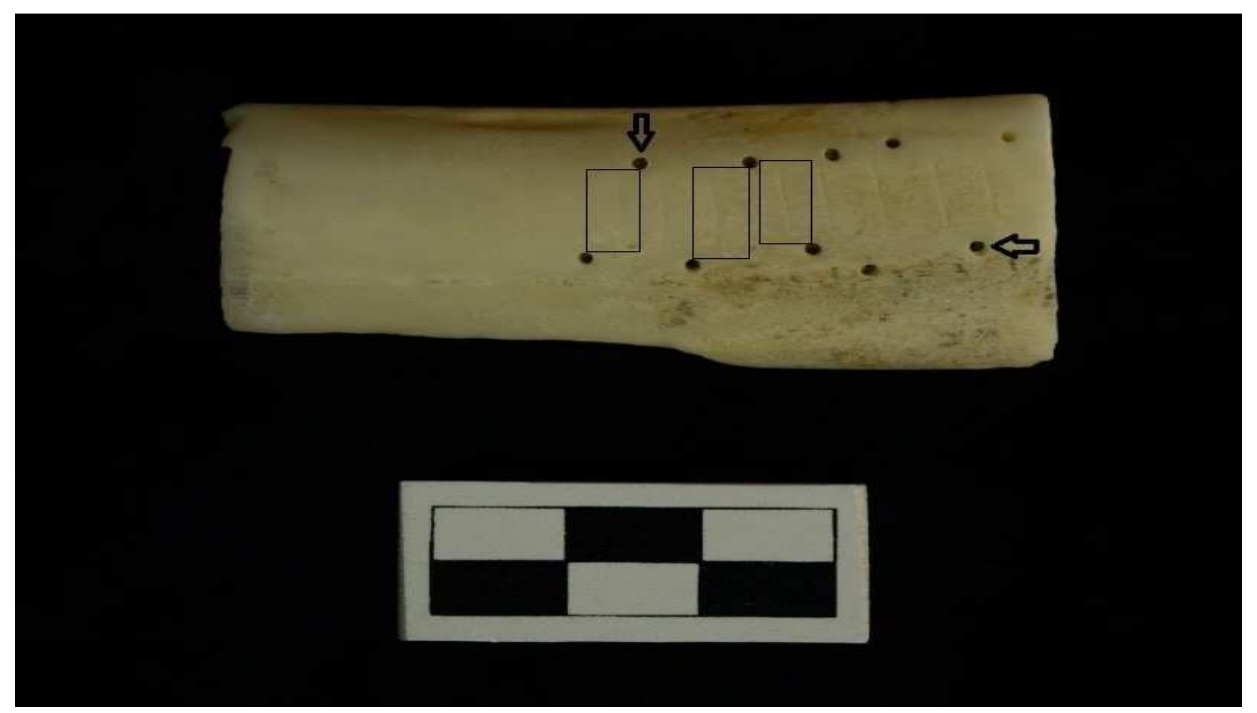

Figure 5. "O" shaped symbols around the cut marks and the borders of the scanned areas. 


\subsubsection{Data processing}

The scans of the marks were processed before taking measurements. The software forms a new studiable after each stage of data processing. "A studiable is a 2-D visual representation of the xyz coordinates for each measured point" (Pante et al., 2017, p.3). The first step of 3-D data processing was filling in non-measured points, which plugged holes in the data resulting from variations in the reflectivity of bone surfaces as described by Pante et al. (2017). For this step, an algorithm was used to fill missing data and smooth the area. The next step was to remove the form of the bone from scans using a polynomial algorithm provided by the software. The mark and a small area around it were excluded from the form removal process to keep the mark morphology unmodified. This algorithm can range from a polynomial degree of 1 to 13 and be changed until the area outside the mark becomes nearly flat. In order to minimize variation between pre-and post-tumbling marks, a polynomial degree of three or four were selected. Form removal is necessary to isolate the borders and deepest points of the marks from the external unmodified bone surface (Pante et al., 2017). However, in some cases (32 cut marks) the polynomial algorithm was ineffective and scans were leveled using a line by line method. Studiables of a cut mark resulted from filling missing data and form removal are shown in Figure 6. The last stage of data processing involved removing data from the scan that extended beyond the length of the mark. 

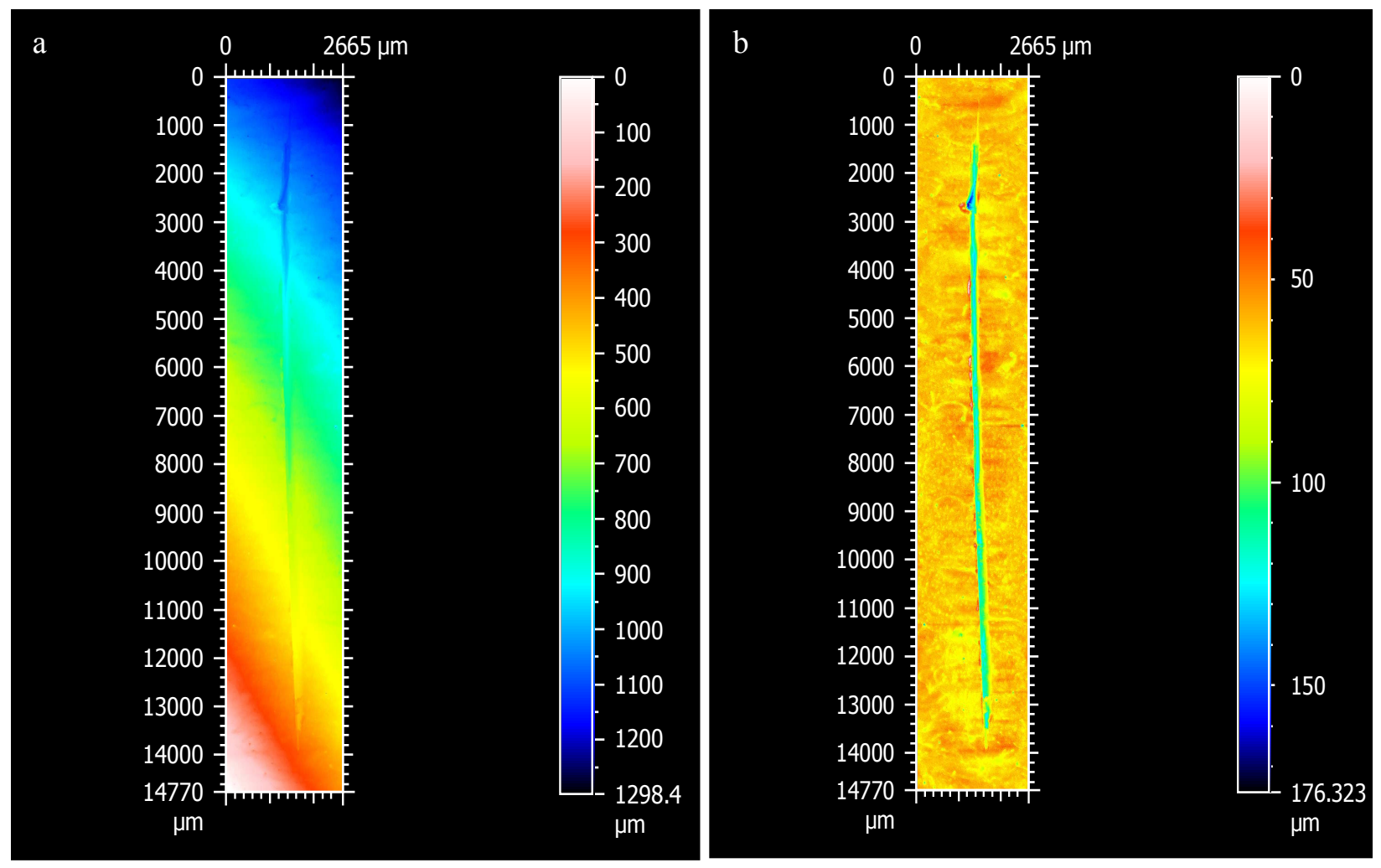

Figure 6. Two studiables from a single cut mark a) studiable formed as a result of filling missing data, b) studiable created by removing form of the bone after missing data was filled. Scales on the figures represent the relationship between color and depth in the studiables.

Cross-sectional 2-D profiles were extracted from scans from the deepest point and center of the marks. The deepest profile was found using the "through lowest point" option in the profile extraction implement of the software. To find the central profile, the total number of profiles intersecting each mark was divided by two.

\subsubsection{Data measurement}

Measurement of scans follows the procedure outlined by Pante et al. (2017). Measurements were collected from both the entire 3-D model and from 2-D profiles extracted from the profile. The 3-D data collection procedure included measurements of surface area, volume, maximum depth, mean depth, maximum length, and maximum width (Figure 7). Details on how these 
measurements are collected using the software can be found in Pante et al. (2017) and are not described further here. Measurements from the 2-D profiles included maximum depth, area, width, roughness, opening angle and floor radius (Figure 8 and Figure 9). To do this the locations of the mark edges on the profile were determined from the 2-D studiables.
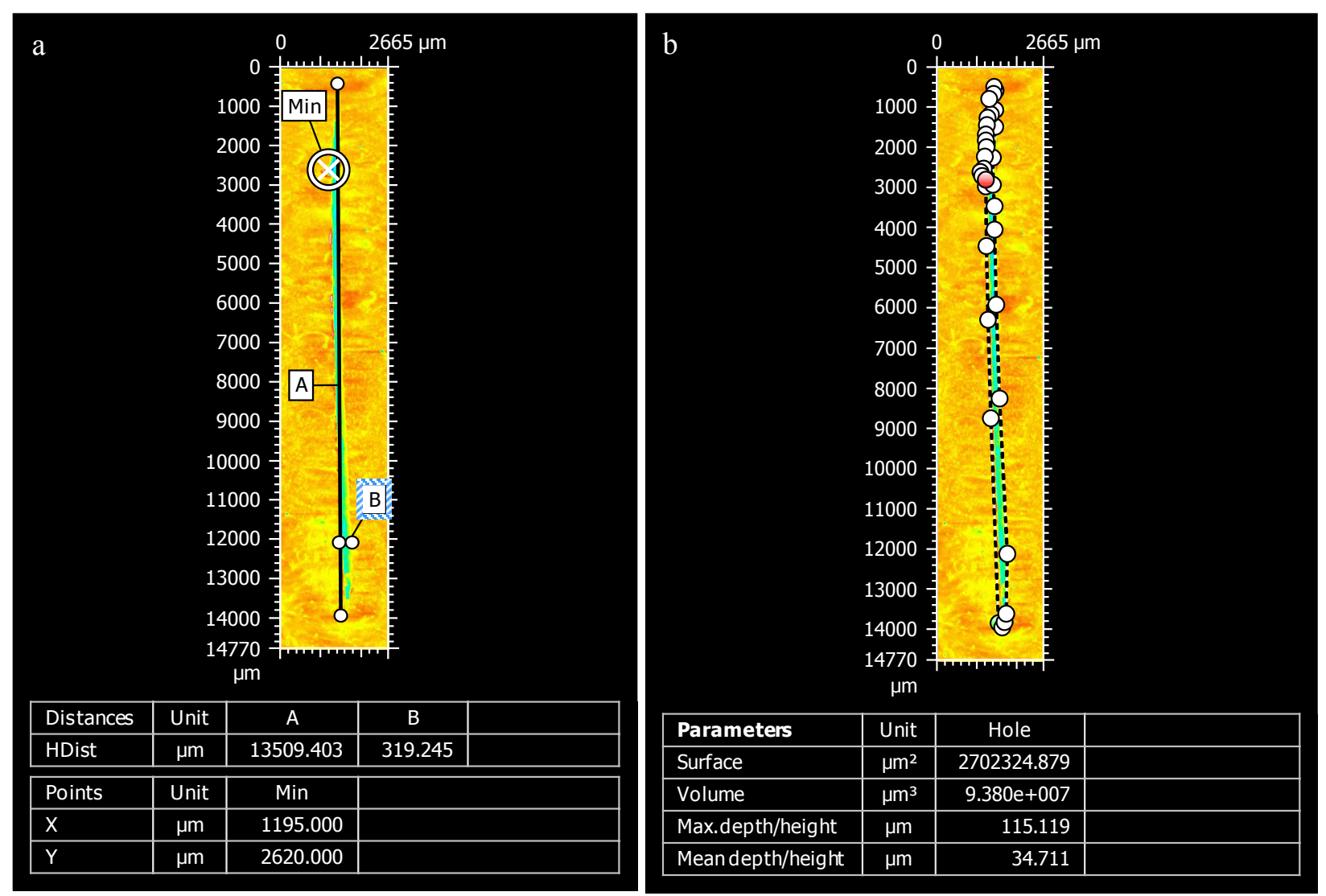

Figure 7. Two studiables from a single cut mark that shows 3-D data measurements based on the studiable shown in Figure $6 \mathrm{~b}$ a) studiable showing the location of the deepest point (at the center of the white circle) and measurements of maximum length and maximum width, b) studiable showing the measurements of surface area, volume, maximum depth, and mean depth. 


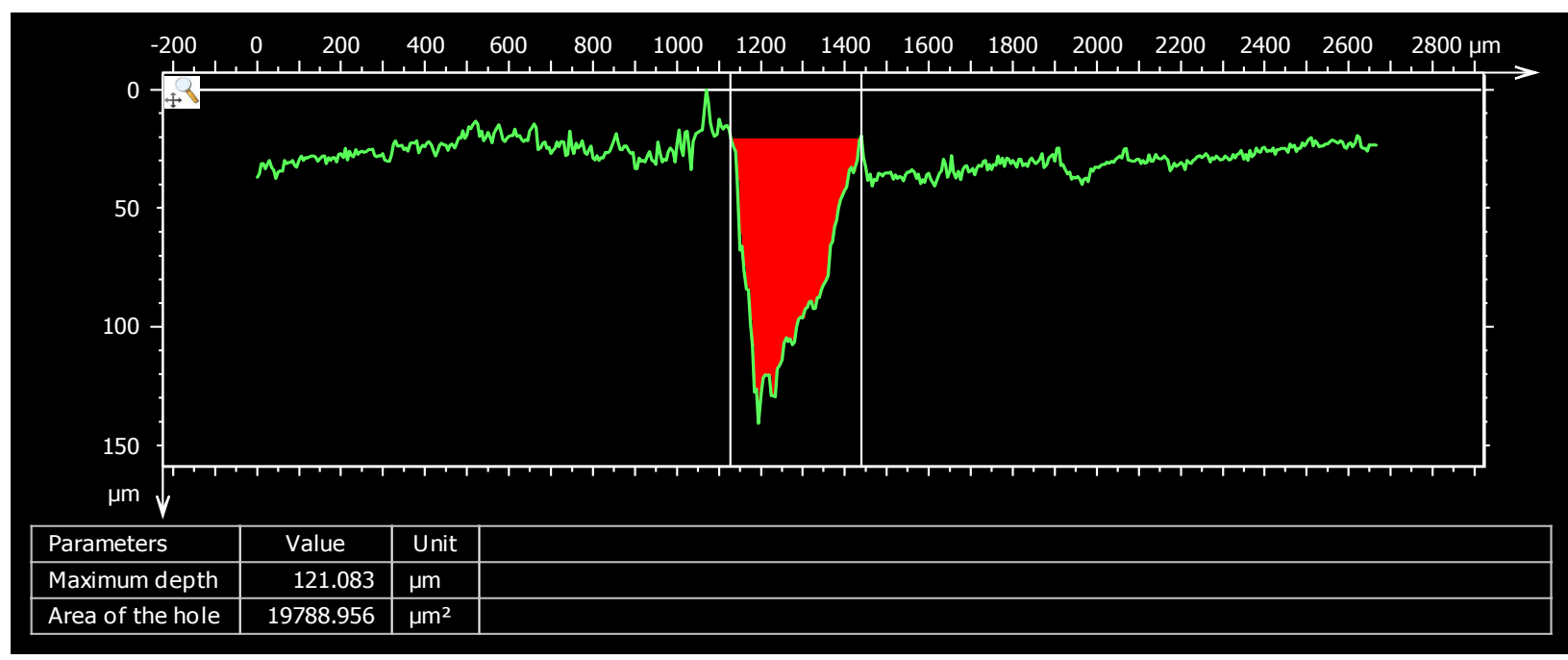

Figure 8. Area of a hole from the cross-sectional profile extracted from the deepest point of a single cut mark based on the studiable shown in Figure $6 b$.

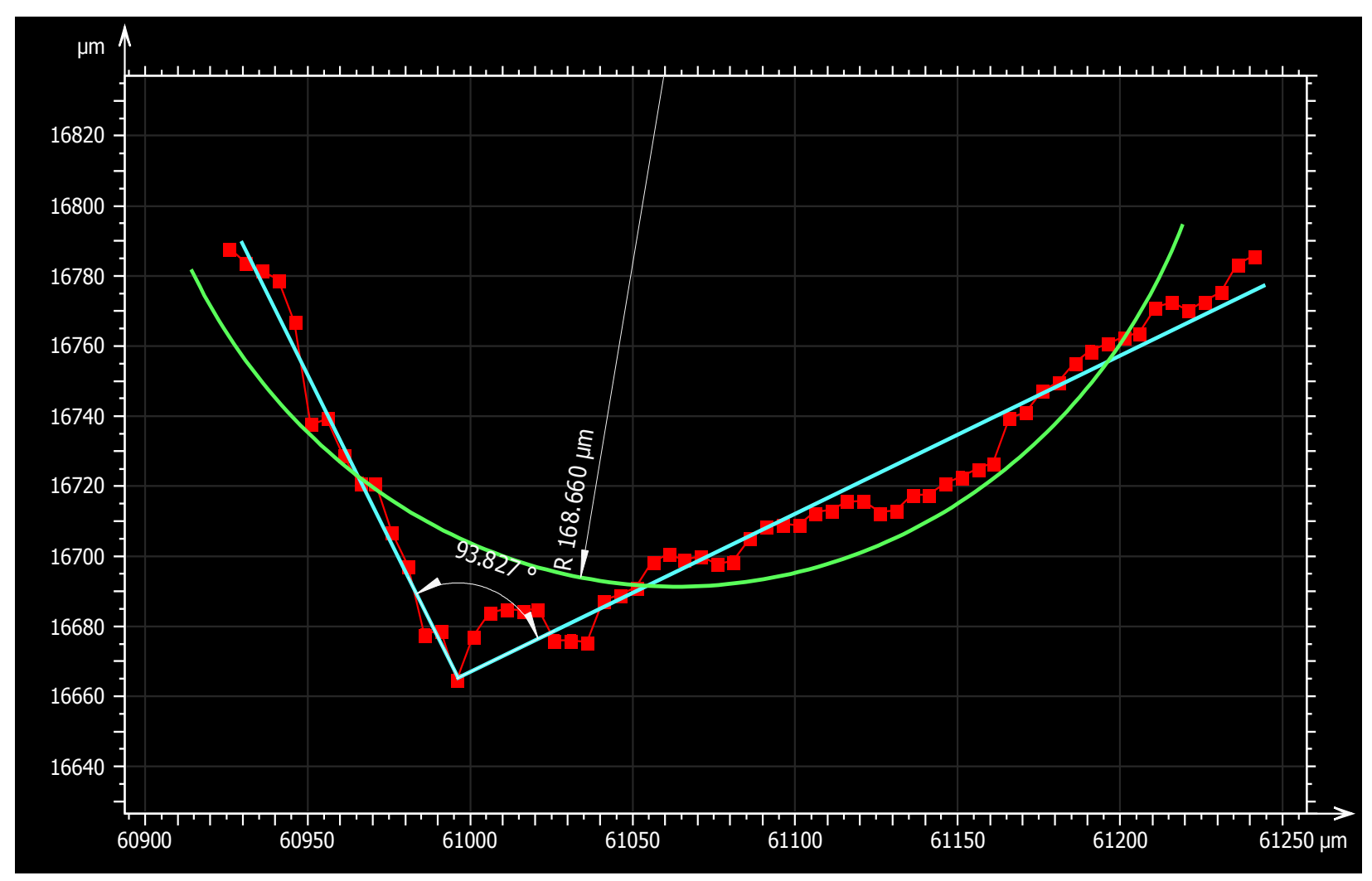

Figure 9. Highlighted part of the cross-sectional profile in Figure 8, showing opening angle and floor radius $(\mathrm{R})$. 


\subsection{Tumbling procedure}

After initial scans and photographs were collected, bones were subjected to tumbling to simulate fluvial abrasion. A low-speed rock tumbler (Thumler's Model B Rock Tumbler) with 15 lb capacity was used for this process. The chamber of the tumbler rotates 21 times per minute and maintains a constant speed. The tumbler was filled with a mixture of $750 \mathrm{ml}$ of poorly sorted sand and $1750 \mathrm{ml}$ of water. This replicate the ratio of sand to water $(0.4286)$ used by Shipman and Rose (1988) (300 $\mathrm{ml}$ of sediment/700 $\mathrm{ml}$ of water) in their tumbling experiments to allow comparisons between our results. The grain size of the minerals ranged from medium to very fine, while the average sphericity and roundness values were estimated to be 0.51 based on Krumbein and Sloss, (1951, p. 111) and Powers (1953, p. 118). This places the sediment particles in the rounded class based on the roundness scale that Powers presented (1953, p.118). The sand used in this experiment was dominated by quartz and also included other minerals such as feldspar and iron rich minerals. The sediment was replaced after each tumbling experiment.

Bones were placed and tumbled with sediment and water in the rock tumbler. Since not all bones could fit in the tumbler, five separate tumbling experiments were performed. For the cattle bones, only two bones were tumbled together for each experiment. For the deer bones, two to three bones were tumbled together. Each trial was run for 152 hours in the tumbler, nearly double that of Shipman and Rose (1983). The long time was selected because after 92 hours of tumbling bone surfaces did not appear to change significantly. Thus, the length of time in the tumbler was extended for all samples.

\subsection{Qualitative analysis after tumbling}

After tumbling, the type and degree of modification occurred on bone surfaces and the bone surface modifications were analyzed. Qualitative analysis started with photographing all samples. 
Then, changes on bone surfaces were recorded by comparing with the photos of the bones taken before tumbling. The next step was to determine whether the marks preserved their diagnostic features based on the criteria used for diagnosing cut marks and carnivore tooth marks (Potts and Shipman, 1981; Shipman and Rose, 1983; Blumenschine et al., 1996). For this purpose, a hand lens with $14 \mathrm{x}$ magnification was used to examine morphology of the marks in detail.

\subsection{Quantitative analysis after tumbling}

Scanning, data processing and data measurement of the bone surface modifications after tumbling followed the same procedure that was carried out before tumbling. However, crosssectional profiles were extracted from four different locations since the locations of the deepest and central point changed for almost all marks after tumbling (Table 2). These four points are the deepest point, the central point, the location with the same $y$ value of the deepest point of the mark before tumbling (extra profile), and the location with the same y value of the central point of the mark before tumbling (extra profile) (Figure 10).

Table 2. The locations that the cross-sectional profiles were extracted from before and after tumbling.

\begin{tabular}{|c|c|c|}
\hline$\stackrel{60}{\Xi}$ & \multicolumn{2}{|c|}{ The deepest point } \\
\hline 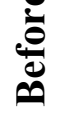 & \multicolumn{2}{|c|}{ The central point } \\
\hline \multirow{4}{*}{ 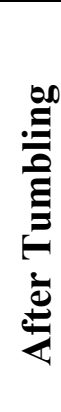 } & \multicolumn{2}{|c|}{ The deepest point } \\
\hline & \multicolumn{2}{|c|}{ The central point } \\
\hline & $1^{\text {st }}$ Extra profile & $\begin{array}{l}\text { The location with the same y value of the } \\
\text { deepest point of the mark before tumbling }\end{array}$ \\
\hline & $2^{\text {nd }}$ Extra profile & $\begin{array}{l}\text { The location with the same y value of the } \\
\text { central point of the mark before tumbling. }\end{array}$ \\
\hline
\end{tabular}




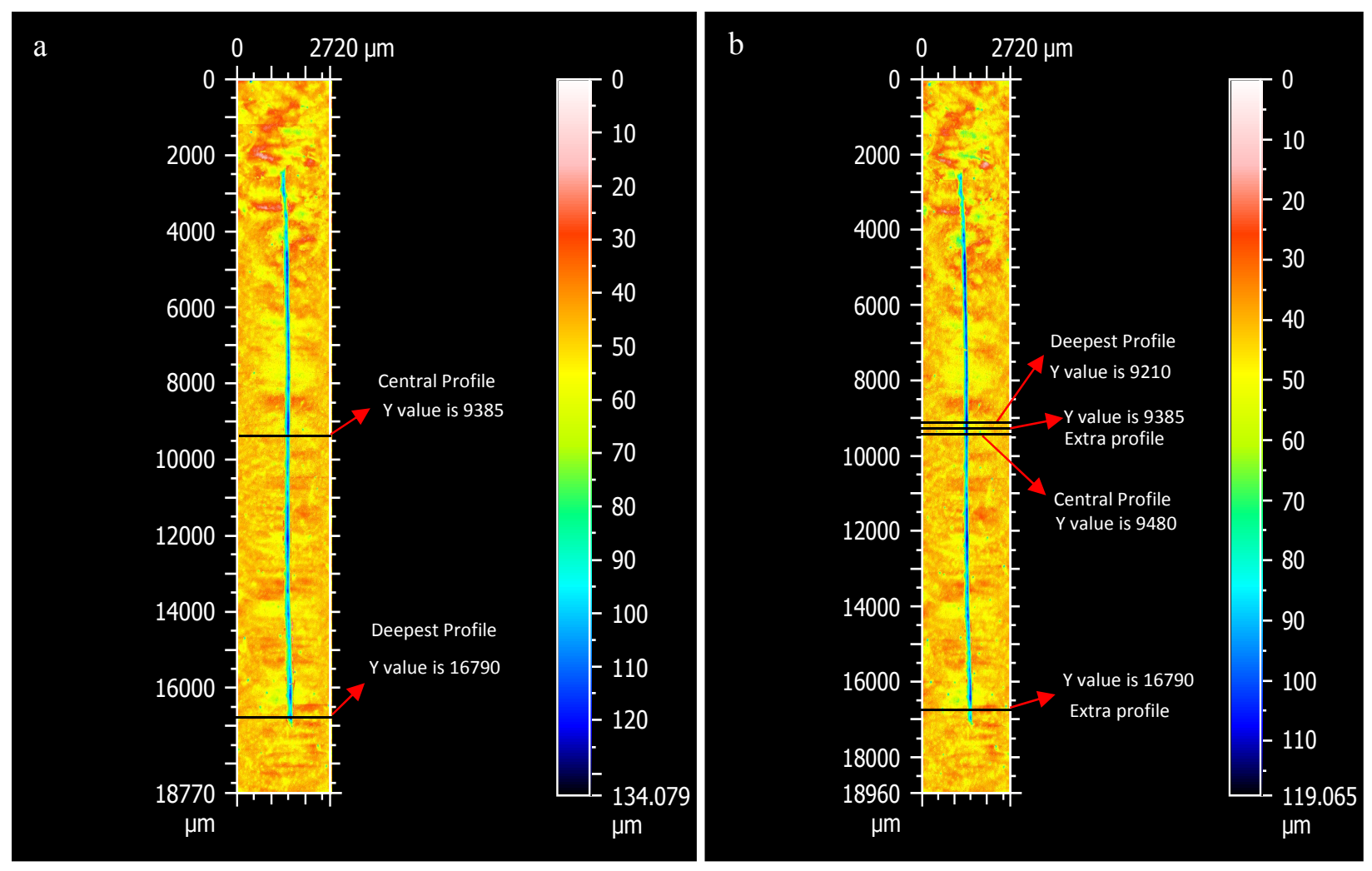

Figure 10. Locations where cross-sectional profiles were taken on extracted scanning surface of a cut mark a) before and b) after tumbling

\subsection{Statistical analysis}

Statistical analyses were performed using Microsoft Excel and PAST-Paleontological Statistics Software Package 3.14 (Hammer et al., 2001). A t-test was applied on Microsoft Excel to determine whether tumbling significantly affected the bone surface modifications. Also, mean, median, and standard deviation values of the mark parameters were measured and recorded. A discriminant analysis (LDA) was performed using the PAST software to identify how accurately cut marks and tooth marks can be differentiated from each other based on the measured variables before and after tumbling. 


\section{CHAPTER 4}

\section{RESULTS}

\subsection{Results of the qualitative analysis}

\subsubsection{Changes in bone morphology from tumbling}

152 hours of tumbling with sand and water affected the general morphology of bone. Abrasion was visible with the naked eye on most bone surfaces. The dominant form of abrasion observed on the bones was ablation, defined as the removal of material from the bone surface by Thompson et al. (2011) and Griffith et al. (2016). Bones also became smoother and polished. The broken edges of some bones were more abraded than their cortical surfaces, while others were abraded more evenly. Some protrusions and crests on bones were highly abraded. For example, a high degree of abrasion was observed on several irregularly-shaped epiphyseal surfaces of two sub-adult deer bones (Figure 11). In addition to these changes, depressions and linear incisions formed on some cattle bones during tumbling, but not on the deer bones (Figure 12). These depressions and incisions are easily differentiated from both the abraded and unabraded tooth marks and cut marks, due to their lack of internal striations and greater width. In one case, exfoliation developed on a bones surface after tumbling (Figure 13). This surface was not exfoliated before abrasion but had several white circular marks on the cortical bone which could have been an indication of an initial stage of exfoliation. 

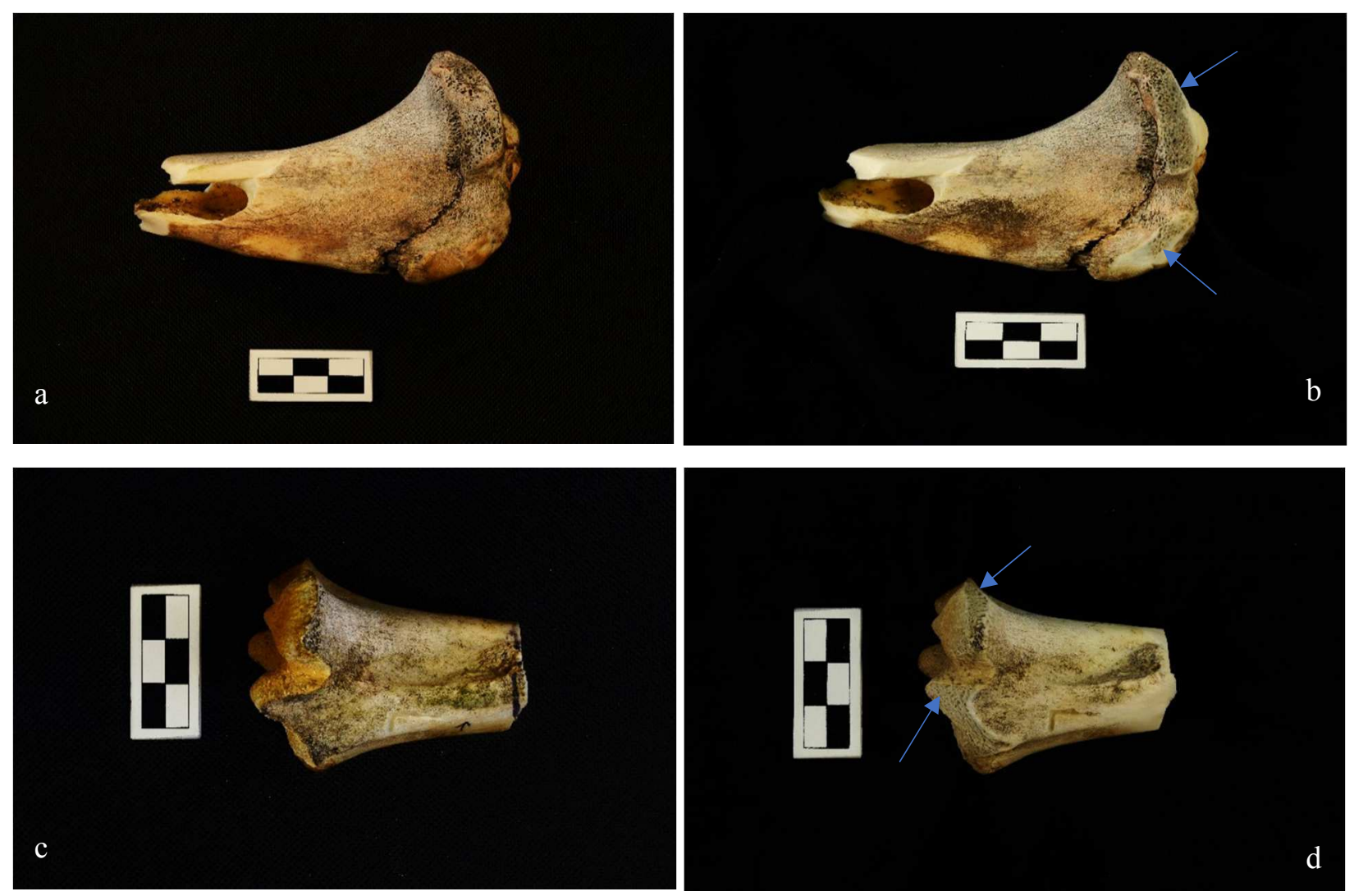

Figure 11. High level of abrasion on the epiphyses of two deer bones. a and c) before tumbling, $b$ and d) after tumbling. Highly abraded areas were shown by the arrows. 

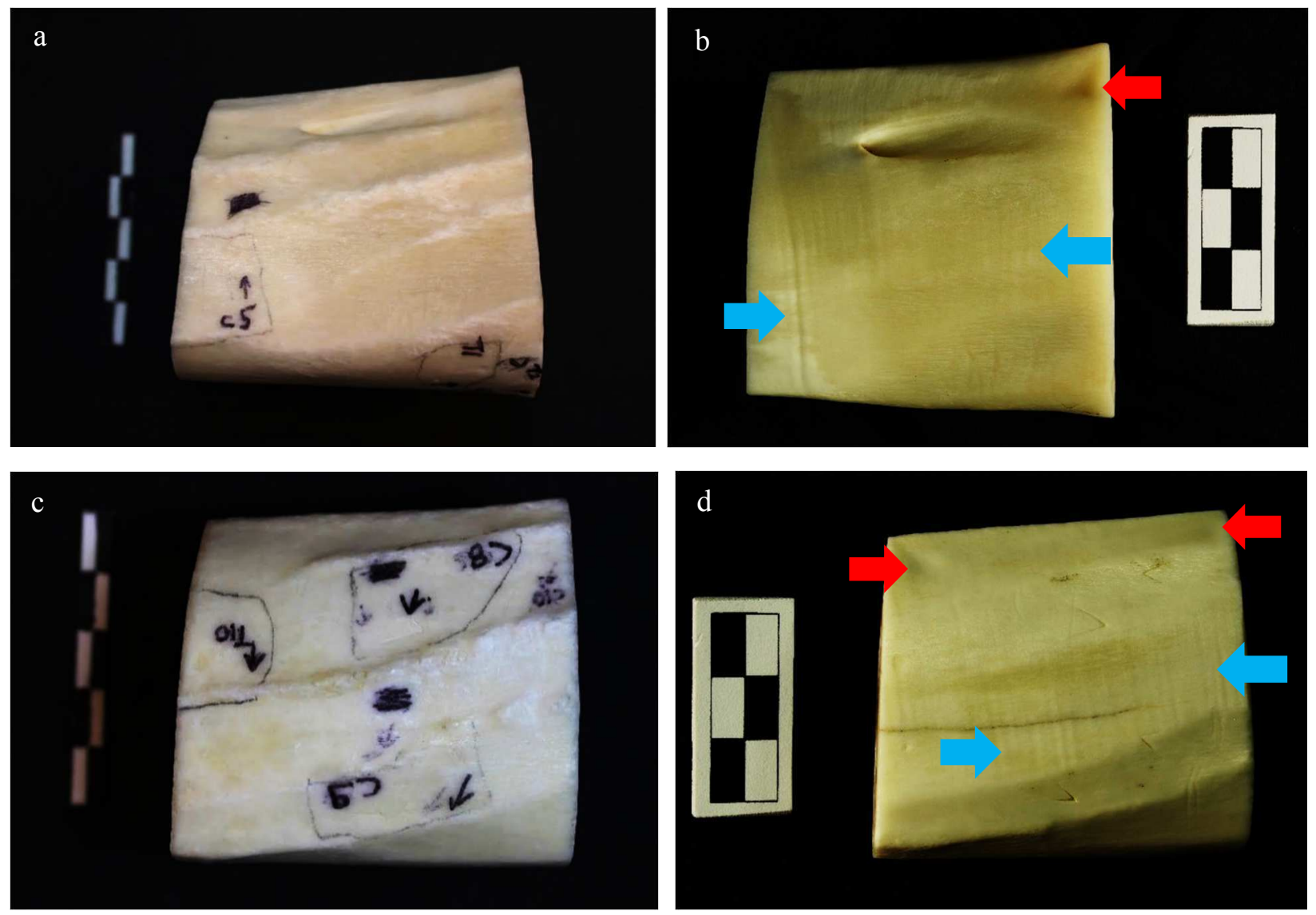

Figure 12. Images of the surfaces of two different cattle bones before and after tumbling. a and c) before tumbling, b and d) after tumbling. Red arrows show the depressions and blues arrows show the straight incisions.

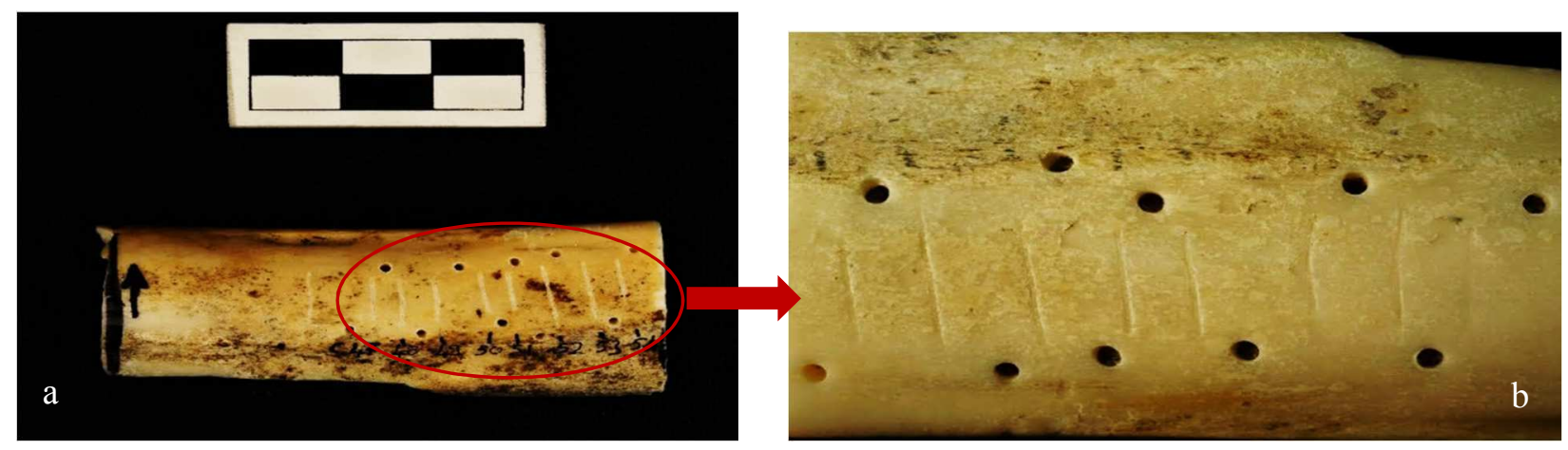

Figure 13. a) the bone surface before tumbling b) exfoliation on the bone surface after tumbling. 


\subsubsection{Changes in mark morphology after tumbling}

After tumbling, most of the cut marks and all of the tooth marks were still visible. Qualitative analysis indicates that 57.1 percent of the cut marks lost internal parallel striations, and 18.4 percent of the cut marks were highly abraded and reduced to rounded indentations. Eight cut marks on the exfoliated surface lost inner striations after tumbling. Also, one cut mark was completely eroded. However, 65.3 percent of the cut marks maintained at least one diagnostic feature. For example, some did not preserve internal striations, but maintained their V-shaped cross-sections, while others had a low breadth: depth ratio, but were not clearly V-shaped. Shoulders, defined as a buildup of bone on the edge of the mark (Bello and Soligo, 2008), were initially present on 30 of 49 cut marks, but after tumbling, the shoulders of 19 of these cut marks were almost or completely dissolved (Figure 14). One hundred percent of the tooth marks preserved at least one diagnostic feature. Only 21.7 percent of the tooth marks lost one diagnostic feature and in all cases it was the crushed internal surface that was lost. 

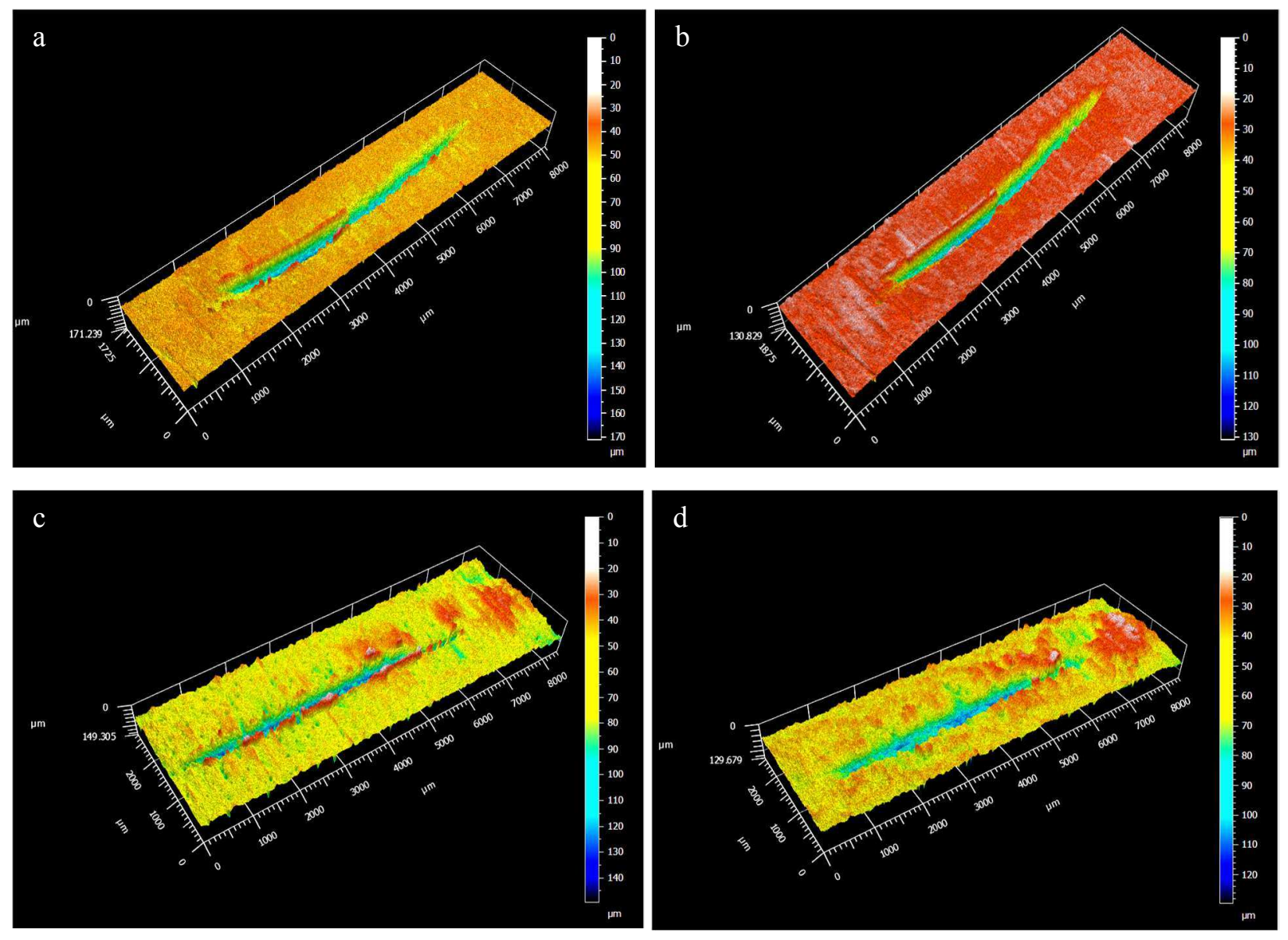

Figure 14. 3-D view of two different cut marks with shoulders, a and b) shows one cut mark before tumbling (a) and after tumbling (b), c and d) shows another cut mark before tumbling (c) and after tumbling (d).

Based on the observations made during this study, a four-stage abrasion scale was created to associate the degree of modification to cut and tooth marks with changes that occur to a bone's surface from fluvial abrasion (Table 3). The stages are associated with the time the bones were in the tumbler. Stage four was not observed during this experiment, but characteristic events of this stage were predicted based on observations reported by other researchers. 
Table 3. The abrasion scale.

\begin{tabular}{|c|c|c|c|c|}
\hline Stage & $\begin{array}{c}\text { Time } \\
\text { (Tumbler) }\end{array}$ & Bone Surface & Cut Marks & Tooth Marks \\
\hline 1 & $10 \mathrm{~h}$ & $\begin{array}{c}\text { Slight polishing, } \\
\text { especially on the } \\
\text { convex surfaces. } \\
\text { Broken edges are } \\
\text { slightly rounded. }\end{array}$ & $\begin{array}{c}\text { They preserve all diagnostic } \\
\text { features. }\end{array}$ & $\begin{array}{c}\text { They preserve all } \\
\text { diagnostic features. }\end{array}$ \\
\hline 2 & $92 \mathrm{~h}$ & $\begin{array}{c}\text { The whole bone } \\
\text { surface is } \\
\text { apparently polished } \\
\text { and smoother. }\end{array}$ & $\begin{array}{c}\text { They are visible and } \\
\text { preserve all diagnostic } \\
\text { features. No apparent } \\
\text { alteration. }\end{array}$ & $\begin{array}{c}\text { They are visible and } \\
\text { preserve all } \\
\text { diagnostic features. } \\
\text { No apparent } \\
\text { alteration. }\end{array}$ \\
\hline 3 & $152 \mathrm{~h}$ & $\begin{array}{c}\text { Highly polished, } \\
\text { but some deep } \\
\text { concave surfaces } \\
\text { remain unchanged. }\end{array}$ & $\begin{array}{c}\text { Most of the cut marks lose } \\
\text { inner striations, but some } \\
\text { still preserve other } \\
\text { characteristic features. Only } \\
\text { a few cut marks became } \\
\text { highly abraded and reduced } \\
\text { to rounded indentations. }\end{array}$ & $\begin{array}{c}\text { Most of them } \\
\text { preserve all } \\
\text { diagnostic features. } \\
\text { A few tooth marks } \\
\text { lost some } \\
\text { characteristic } \\
\text { features. }\end{array}$ \\
\hline 4 & $\begin{array}{c}\text { More } \\
\text { than } 250 \\
\mathrm{~h}\end{array}$ & $\begin{array}{c}\text { High degree of } \\
\text { abrasion. Broken } \\
\text { edges are highly } \\
\text { rounded. Small } \\
\text { bone fractures } \\
\text { become pebble- } \\
\text { shaped. }\end{array}$ & $\begin{array}{c}\text { Theatures and become } \\
\text { unidentifiable. }\end{array}$ & $\begin{array}{c}\text { Most of them lose } \\
\text { diagnostic features } \\
\text { and become } \\
\text { unidentifiable, but } \\
\text { some may still be } \\
\text { identifiable. }\end{array}$ \\
\hline
\end{tabular}

\subsection{Results of the quantitative analysis}

\subsubsection{3-D measurements}

Mean values of the measured parameters of the cut marks indicate that surface area, volume, and maximum width increased while maximum depth, mean depth, and maximum length decreased after tumbling. The T-tests employed for cut mark parameters indicate that surface area, maximum depth, mean depth, maximum length, and maximum width changed significantly after tumbling, while volume did not show a significant change. The increase in width and decrease in 
mean depth and maximum length show that the cut marks became wider, shorter, and shallower after tumbling.

Mean values for the tooth marks display that volume, maximum depth, mean depth, maximum length, and maximum width increased, while only surface area decreased. Results of the T-tests show that none of the tooth mark parameters indicated a significant change after tumbling. Summary statistics and the results of t-test for 3-D measurements are found in Table 4 and Table 5.

\subsubsection{Profile measurements}

Mean values of the profile measurements from the cut marks show that maximum width, angle, and radius increased while maximum depth, area, and roughness decreased after tumbling. Results of the T-tests present that maximum depth, maximum width, roughness, angle, and radius values of the cut marks changed significantly after tumbling, while area for most profiles did not show a significant change.

Mean values of the tooth mark parameters are inconclusive because they are not consistent between profile measurements (Table 4). For instance, the mean area values of tooth marks show an increase after tumbling for the deepest and central profiles, but indicate a decrease for the deepest and central profiles which used measurements from the extra profiles (Table 4.b and 4.c). The t-tests show that only maximum depth values measured from the deepest profiles indicate a significant change after abrasion. Summary statistics and the results of T-test for the profile measurements are found in Table 4 and Table 5. 
Table 4 . Summary statistics. Mean, median, and standard deviation of the measurements of cut marks and tooth marks before and after tumbling. $\mathrm{R}_{\mathrm{a}}$ refers to roughness.

\begin{tabular}{|c|c|c|c|c|c|c|c|c|c|c|c|c|c|}
\hline \multicolumn{2}{|c|}{ Table 4.a } & \multicolumn{6}{|c|}{ Measurements from 3-D studiables (before tumbling) } & \multicolumn{6}{|c|}{ Measurements from 3-D studiables (after tumbling) } \\
\hline & & $\begin{array}{c}\text { Surface } \\
\text { Area } \\
\left(\mu \mathrm{m}^{2}\right)\end{array}$ & $\begin{array}{c}\text { Volume } \\
\left(\mu \mathrm{m}^{3}\right)\end{array}$ & $\begin{array}{l}\text { Maximum } \\
\text { Depth } \\
(\mu \mathrm{m})\end{array}$ & $\begin{array}{c}\text { Mean } \\
\text { Depth } \\
(\mu \mathrm{m})\end{array}$ & $\begin{array}{l}\text { Maximum } \\
\text { Length } \\
(\mu \mathrm{m})\end{array}$ & $\begin{array}{l}\text { Maximum } \\
\text { Width } \\
(\mu \mathrm{m})\end{array}$ & $\begin{array}{c}\text { Surface } \\
\text { Area } \\
\left(\mu \mathrm{m}^{2}\right)\end{array}$ & $\begin{array}{c}\text { Volume } \\
\left(\mu \mathrm{m}^{3}\right)\end{array}$ & $\begin{array}{l}\text { Maximum } \\
\text { Depth } \\
(\mu \mathrm{m})\end{array}$ & $\begin{array}{c}\text { Mean } \\
\text { Depth } \\
(\mu \mathrm{m})\end{array}$ & $\begin{array}{l}\text { Maximum } \\
\text { Length } \\
(\mu \mathrm{m})\end{array}$ & $\begin{array}{l}\text { Maximum } \\
\text { Width } \\
(\mu \mathrm{m})\end{array}$ \\
\hline \multirow{3}{*}{ U } & 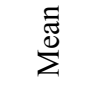 & 2318825.4 & 85015510.2 & 106.7 & 37.0 & 8195.3 & 435.0 & 2873198.3 & 86507551.0 & 93.0 & 32.3 & 7995.0 & 529.7 \\
\hline & $\stackrel{\text { : }}{:}$ & 2119949.9 & 83440000.0 & 106.7 & 37.9 & 7567.1 & 426.2 & 2546949.9 & 83120000.0 & 91.5 & 34.8 & 7483.5 & 477.0 \\
\hline & $\dot{\omega} \overrightarrow{0}$ & 752454.4 & 30436985.2 & 17.7 & 8.1 & 2675.8 & 114.7 & 1405364.4 & 31823959.8 & 23.3 & 9.7 & 2676.3 & 173.4 \\
\hline \multirow{3}{*}{ 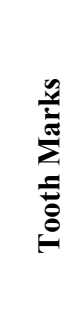 } & 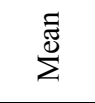 & 8507028.1 & 657563478.3 & 218.0 & 71.0 & 6748.2 & 2228.7 & 8375263.9 & 671333913.0 & 237.2 & 75.0 & 6771.5 & 2290.4 \\
\hline & 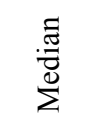 & 6563124.7 & 454500000.0 & 204.9 & 65.8 & 5922.4 & 1943.5 & 6671974.7 & 469100000.0 & 212.7 & 68.2 & 6101.9 & 2098.3 \\
\hline & 漓 己⿱艹 & 7440951.0 & 777184933.9 & 92.1 & 29.4 & 4418.9 & 1105.7 & 6133207.2 & 677892696.8 & 95.8 & 28.9 & 4179.8 & 1010.0 \\
\hline
\end{tabular}




\begin{tabular}{|c|c|c|c|c|c|c|c|c|c|c|c|c|c|c|c|c|c|c|c|}
\hline \multicolumn{2}{|c|}{ Table 4.b } & \multicolumn{6}{|c|}{$\begin{array}{l}\text { Measurements from deepest profile } \\
\text { (before tumbling) }\end{array}$} & \multicolumn{6}{|c|}{$\begin{array}{l}\text { Measurements from deepest profile } \\
\text { (after tumbling) }\end{array}$} & \multicolumn{6}{|c|}{ Measurements from $1^{\text {st }}$ extra profiles } \\
\hline & & $\begin{array}{l}\text { Max. } \\
\text { Depth } \\
(\mu \mathrm{m})\end{array}$ & $\begin{array}{c}\text { Area } \\
\left(\mu \mathrm{m}^{2}\right)\end{array}$ & $\begin{array}{l}\text { Max. } \\
\text { Width } \\
(\mu \mathrm{m})\end{array}$ & $\mathrm{R}_{\mathrm{a}}$ & $\begin{array}{c}\text { Angle } \\
\left(^{\circ}\right)\end{array}$ & $\begin{array}{l}\text { Radius } \\
(\mu \mathrm{m})\end{array}$ & $\begin{array}{l}\text { Max. } \\
\text { Depth } \\
(\mu \mathrm{m})\end{array}$ & $\begin{array}{c}\text { Area } \\
\left(\mu \mathrm{m}^{2}\right)\end{array}$ & $\begin{array}{l}\text { Max. } \\
\text { Width } \\
(\mu \mathrm{m})\end{array}$ & $\mathrm{R}_{\mathrm{a}}$ & $\begin{array}{c}\text { Angle } \\
\left({ }^{\circ}\right)\end{array}$ & $\begin{array}{c}\text { Radius } \\
(\mu \mathrm{m})\end{array}$ & $\begin{array}{l}\text { Max. } \\
\text { Depth } \\
(\mu \mathrm{m})\end{array}$ & $\begin{array}{c}\text { Area } \\
\left(\mu \mathrm{m}^{2}\right)\end{array}$ & $\begin{array}{l}\text { Max. } \\
\text { Width } \\
(\mu \mathrm{m})\end{array}$ & $\mathrm{R}_{\mathrm{a}}$ & $\begin{array}{c}\text { Angle } \\
\left({ }^{\circ}\right)\end{array}$ & $\begin{array}{c}\text { Radius } \\
(\mu \mathrm{m})\end{array}$ \\
\hline \multirow{3}{*}{ 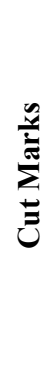 } & $\stackrel{\Xi \Xi}{\Sigma}$ & 103.1 & 16570.9 & 345.0 & 3.2 & 118.1 & 280.0 & 86.5 & 16512.8 & 427.4 & 2.9 & 131.9 & 607.3 & 68.2 & 15344.3 & 430.1 & 2.1 & 140.1 & 717.9 \\
\hline & 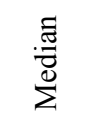 & 101.4 & 16084.8 & 330.0 & 2.9 & 119.0 & 225.2 & 86.7 & 16838.4 & 395.0 & 2.3 & 136.7 & 356.3 & 67.6 & 14421.6 & 435.0 & 1.9 & 145.5 & 391.0 \\
\hline & $\begin{array}{l}\overrightarrow{0} \\
\dot{\omega} \\
\dot{n}\end{array}$ & 21.6 & 6604.1 & 84.0 & 1.1 & 18.6 & 160.9 & 23.5 & 6734.8 & 158.5 & 1.3 & 22.6 & 854.4 & 21.1 & 6230.0 & 145.5 & 0.9 & 19.1 & 1047.4 \\
\hline \multirow{3}{*}{ 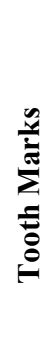 } & $\sum_{\Sigma}^{\Xi ี \Xi}$ & 218.1 & 244300.8 & 1991.5 & 6.6 & 154.7 & 3832.4 & 236.9 & 259804.7 & 1960.0 & 7.0 & 154.1 & 3204.8 & 193.7 & 214971.4 & 1873.3 & 6.1 & 155.9 & 14802.6 \\
\hline & 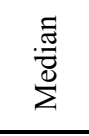 & 208.4 & 217165.1 & 2000.0 & 5.2 & 155.8 & 2260.8 & 213.6 & 225708.9 & 1730.0 & 6.7 & 156.2 & 2509.5 & 172.7 & 159613.7 & 1630.0 & 5.3 & 157.7 & 2463.4 \\
\hline & $\dot{\omega} \overrightarrow{0}$ & 94.7 & 210584.3 & 892.8 & 4.0 & 8.6 & 3481.7 & 96.5 & 201504.5 & 832.6 & 4.1 & 10.0 & 2563.9 & 93.1 & 170918.6 & 728.8 & 3.2 & 10.4 & 54095.0 \\
\hline
\end{tabular}




\begin{tabular}{|c|c|c|c|c|c|c|c|c|c|c|c|c|c|c|c|c|c|c|c|}
\hline \multicolumn{2}{|c|}{ Table 4.c } & \multicolumn{6}{|c|}{$\begin{array}{l}\text { Measurements from central profile } \\
\text { (before tumbling) }\end{array}$} & \multicolumn{6}{|c|}{$\begin{array}{l}\text { Measurements from central profile } \\
\text { (after tumbling) }\end{array}$} & \multicolumn{6}{|c|}{ Measurements from $2^{\text {nd }}$ extra profiles } \\
\hline & & $\begin{array}{l}\text { Max. } \\
\text { Depth } \\
(\mu \mathrm{m})\end{array}$ & $\begin{array}{c}\text { Area } \\
\left(\mu \mathrm{m}^{2}\right)\end{array}$ & $\begin{array}{l}\text { Max. } \\
\text { Width } \\
(\mu \mathrm{m})\end{array}$ & $\mathrm{R}_{\mathrm{a}}$ & $\begin{array}{c}\text { Angle } \\
\left(^{\circ}\right)\end{array}$ & $\begin{array}{l}\text { Radius } \\
(\mu \mathrm{m})\end{array}$ & $\begin{array}{l}\text { Max. } \\
\text { Depth } \\
(\mu \mathrm{m})\end{array}$ & $\begin{array}{l}\text { Area } \\
\left(\mu \mathrm{m}^{2}\right)\end{array}$ & $\begin{array}{l}\text { Max. } \\
\text { Width } \\
(\mu \mathrm{m})\end{array}$ & $\mathrm{R}_{\mathrm{a}}$ & $\begin{array}{c}\text { Angle } \\
\left({ }^{\circ}\right)\end{array}$ & $\begin{array}{c}\text { Radius } \\
(\mu \mathrm{m})\end{array}$ & $\begin{array}{l}\text { Max. } \\
\text { Depth } \\
(\mu \mathrm{m})\end{array}$ & $\begin{array}{c}\text { Area } \\
\left(\mu \mathrm{m}^{2}\right)\end{array}$ & $\begin{array}{l}\text { Max. } \\
\text { Width } \\
(\mu \mathrm{m})\end{array}$ & $\mathrm{R}_{\mathrm{a}}$ & $\begin{array}{c}\text { Angle } \\
\left({ }^{\circ}\right)\end{array}$ & $\begin{array}{l}\text { Radius } \\
(\mu \mathrm{m})\end{array}$ \\
\hline \multirow{3}{*}{ 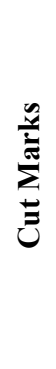 } & $\stackrel{\Xi \Xi}{\Sigma}$ & 69.6 & 13550.0 & 338.3 & 2.2 & 126.3 & 484.1 & 57.6 & 11721.0 & 391.4 & 1.7 & 141.1 & 968.0 & 58.5 & 12411.4 & 403.9 & 1.8 & 141.2 & 985.8 \\
\hline & 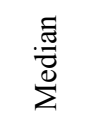 & 71.3 & 11948.3 & 340.0 & 2.1 & 126.9 & 267.0 & 58.7 & 10331.5 & 385.0 & 1.6 & 144.7 & 382.3 & 59.3 & 10767.5 & 415.0 & 1.7 & 143.9 & 454.1 \\
\hline & $\begin{array}{l}\overrightarrow{0} \\
\dot{\omega} \\
\dot{n}\end{array}$ & 18.8 & 6622.7 & 101.2 & 0.8 & 17.7 & 662.4 & 20.1 & 5141.7 & 154.5 & 0.5 & 19.1 & 1995.6 & 20.2 & 5890.1 & 134.7 & 0.7 & 19.2 & 1941.6 \\
\hline \multirow{3}{*}{ 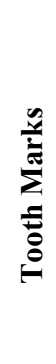 } & $\sum_{\Sigma}^{\Xi ี \Xi}$ & 94.0 & 75795.0 & 1335.7 & 3.3 & 164.8 & 4150.4 & 101.1 & 76352.5 & 1340.9 & 3.8 & 162.0 & 3703.3 & 101.2 & 72539.3 & 1276.1 & 3.5 & 163.4 & 3694.2 \\
\hline & 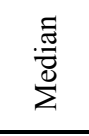 & 80.6 & 47631.4 & 1045.0 & 2.5 & 165.8 & 2856.9 & 94.1 & 57256.1 & 1045.0 & 3.0 & 162.9 & 2680.0 & 84.4 & 47662.9 & 1050.0 & 3.0 & 163.6 & 2310.6 \\
\hline & $\dot{\omega} \overrightarrow{0}$ & 48.7 & 70577.7 & 694.7 & 1.9 & 5.4 & 4653.8 & 45.6 & 63931.3 & 628.8 & 2.0 & 8.7 & 4208.9 & 64.2 & 66676.6 & 602.3 & 2.2 & 6.3 & 5148.0 \\
\hline
\end{tabular}


Table 5. T-tests comparing the measurements of tooth and cut marks before and after tumbling. 5.a) for 3-D measurements, 5.b) for deepest profiles, 5.c) for central profiles, 5.d) for deepest profiles with extra profiles, 5.e) for central profiles with extra profiles.

\begin{tabular}{|c|c|c|c|c|c|c|}
\hline \multicolumn{2}{|c|}{ Table 5.a: t-test comparison of mark parameters before and after tumbling } \\
\hline & $\begin{array}{c}\text { Surface } \\
\text { Area } \\
\left(\boldsymbol{\mu \mathbf { m } ^ { 2 } )}\right.\end{array}$ & $\begin{array}{c}\text { Volume } \\
\left(\boldsymbol{\mu m}^{\mathbf{3}}\right)\end{array}$ & $\begin{array}{c}\text { Maximum } \\
\text { Depth } \\
(\boldsymbol{\mu m})\end{array}$ & $\begin{array}{c}\text { Mean } \\
\text { Depth } \\
(\boldsymbol{\mu m})\end{array}$ & $\begin{array}{c}\text { Maximum } \\
\text { Length } \\
(\boldsymbol{\mu m})\end{array}$ & $\begin{array}{c}\text { Maximum } \\
\text { Width } \\
(\boldsymbol{\mu m})\end{array}$ \\
\hline $\begin{array}{c}\text { Cut } \\
\text { Marks }\end{array}$ & 0.0002 & 0.45 & 0.0001 & $<0.0001$ & 0.005 & $<0.0001$ \\
\hline $\begin{array}{c}\text { Tooth } \\
\text { Marks }\end{array}$ & 0.70 & 0.69 & 0.06 & 0.20 & 0.82 & 0.20 \\
\hline
\end{tabular}

\begin{tabular}{|c|c|r|r|r|r|r|}
\hline \multicolumn{7}{|c|}{ Table 5.b: t-test comparison of mark parameters before and after tumbling } \\
\hline & $\begin{array}{c}\text { Maximum } \\
\text { Depth } \\
(\boldsymbol{\mu m})\end{array}$ & $\begin{array}{c}\text { Area } \\
\left(\boldsymbol{\mu m}^{\mathbf{2}}\right)\end{array}$ & $\begin{array}{c}\text { Maximum } \\
\text { Width } \\
(\boldsymbol{\mu m})\end{array}$ & $\begin{array}{c}\text { Roughness } \\
\left(\mathbf{R}_{\mathbf{a}}\right)\end{array}$ & $\begin{array}{c}\text { Angle } \\
\left({ }^{\circ}\right)\end{array}$ & $\begin{array}{c}\text { Radius } \\
(\boldsymbol{\mu m})\end{array}$ \\
\hline $\begin{array}{c}\text { Cut } \\
\text { Marks }\end{array}$ & $<0.0001$ & 0.96 & 0.0003 & 0.16 & 0.0003 & 0.005 \\
\hline $\begin{array}{c}\text { Tooth } \\
\text { Marks }\end{array}$ & 0.03 & 0.39 & 0.68 & 0.65 & 0.57 & 0.27 \\
\hline
\end{tabular}

\begin{tabular}{|c|c|r|r|r|r|r|}
\hline \multicolumn{2}{|c|}{ Table 5.c: t-test comparison of mark parameters before and after tumbling } \\
\hline & $\begin{array}{c}\text { Maximum } \\
\text { Depth } \\
(\boldsymbol{\mu m})\end{array}$ & $\begin{array}{c}\text { Area } \\
\left(\boldsymbol{\mu m}^{\mathbf{2}}\right)\end{array}$ & $\begin{array}{c}\text { Maximum } \\
\text { Width } \\
(\boldsymbol{\mu m})\end{array}$ & $\begin{array}{c}\text { Roughness } \\
(\mathbf{R})\end{array}$ & $\begin{array}{c}\text { Angle } \\
\left(\mathbf{\circ}^{\mathbf{m}}\right)\end{array}$ & $\begin{array}{c}\text { Radius } \\
(\boldsymbol{\mu m})\end{array}$ \\
\hline $\begin{array}{c}\text { Cut } \\
\text { Marks }\end{array}$ & $<0.0001$ & 0.02 & 0.02 & 0.003 & $<0.0001$ & 0.03 \\
\hline $\begin{array}{c}\text { Tooth } \\
\text { Marks }\end{array}$ & 0.17 & 0.92 & 0.95 & 0.26 & 0.18 & 0.45 \\
\hline
\end{tabular}

\begin{tabular}{|c|c|r|r|r|r|r|}
\hline \multicolumn{2}{|c|}{ Table 5.d: t-test comparison of mark parameters before and after tumbling } \\
\hline & $\begin{array}{c}\text { Maximum } \\
\text { Depth } \\
(\boldsymbol{\mu m})\end{array}$ & $\begin{array}{c}\text { Area } \\
\left(\boldsymbol{\mu m}^{\mathbf{2}}\right)\end{array}$ & $\begin{array}{c}\text { Maximum } \\
\text { Width } \\
(\boldsymbol{\mu m})\end{array}$ & $\begin{array}{c}\text { Roughness } \\
\left(\mathbf{R}_{\mathbf{a}}\right)\end{array}$ & $\begin{array}{c}\text { Angle } \\
\left({ }^{\circ}\right)\end{array}$ & $\begin{array}{c}\text { Radius } \\
(\boldsymbol{\mu m})\end{array}$ \\
\hline $\begin{array}{c}\text { Cut } \\
\text { Marks }\end{array}$ & $<0.0001$ & 0.19 & $<0.0001$ & $<0.0001$ & $<0.0001$ & 0.002 \\
\hline $\begin{array}{c}\text { Tooth } \\
\text { Marks }\end{array}$ & 0.02 & 0.13 & 0.17 & 0.42 & 0.48 & 0.35 \\
\hline
\end{tabular}




\begin{tabular}{|c|c|c|r|r|r|r|}
\hline \multicolumn{7}{|c|}{ Table 5.e: t-test comparison of mark parameters before and after tumbling } \\
\hline & $\begin{array}{c}\text { Maximum } \\
\text { Depth } \\
(\boldsymbol{\mu m})\end{array}$ & $\begin{array}{c}\text { Area } \\
\left(\boldsymbol{\mu \mathbf { m } ^ { 2 } )}\right.\end{array}$ & $\begin{array}{c}\text { Maximum } \\
\text { Width } \\
(\boldsymbol{\mu m})\end{array}$ & $\begin{array}{c}\text { Roughness } \\
\left(\mathbf{R}_{\mathbf{a}}\right)\end{array}$ & $\begin{array}{c}\text { Angle } \\
\left({ }^{\circ}\right)\end{array}$ & $\begin{array}{c}\text { Radius } \\
(\boldsymbol{\mu m})\end{array}$ \\
\hline $\begin{array}{c}\text { Cut } \\
\text { Marks }\end{array}$ & $<0.0001$ & 0.15 & 0.0005 & 0.01 & $<0.0001$ & 0.02 \\
\hline $\begin{array}{c}\text { Tooth } \\
\text { Marks }\end{array}$ & 0.43 & 0.71 & 0.57 & 0.58 & 0.32 & 0.5 \\
\hline
\end{tabular}




\subsection{Cut mark vs. tooth mark}

Multivariate linear discriminant analysis (LDA) was performed using the all measured parameters of the marks to find out how accurately cut marks and tooth marks can be distinguished from each other before and after tumbling. Results of the discriminant analysis show that the cut marks and tooth marks can be distinguished from each other with $100 \%$ accuracy before and after tumbling (Figure 15).
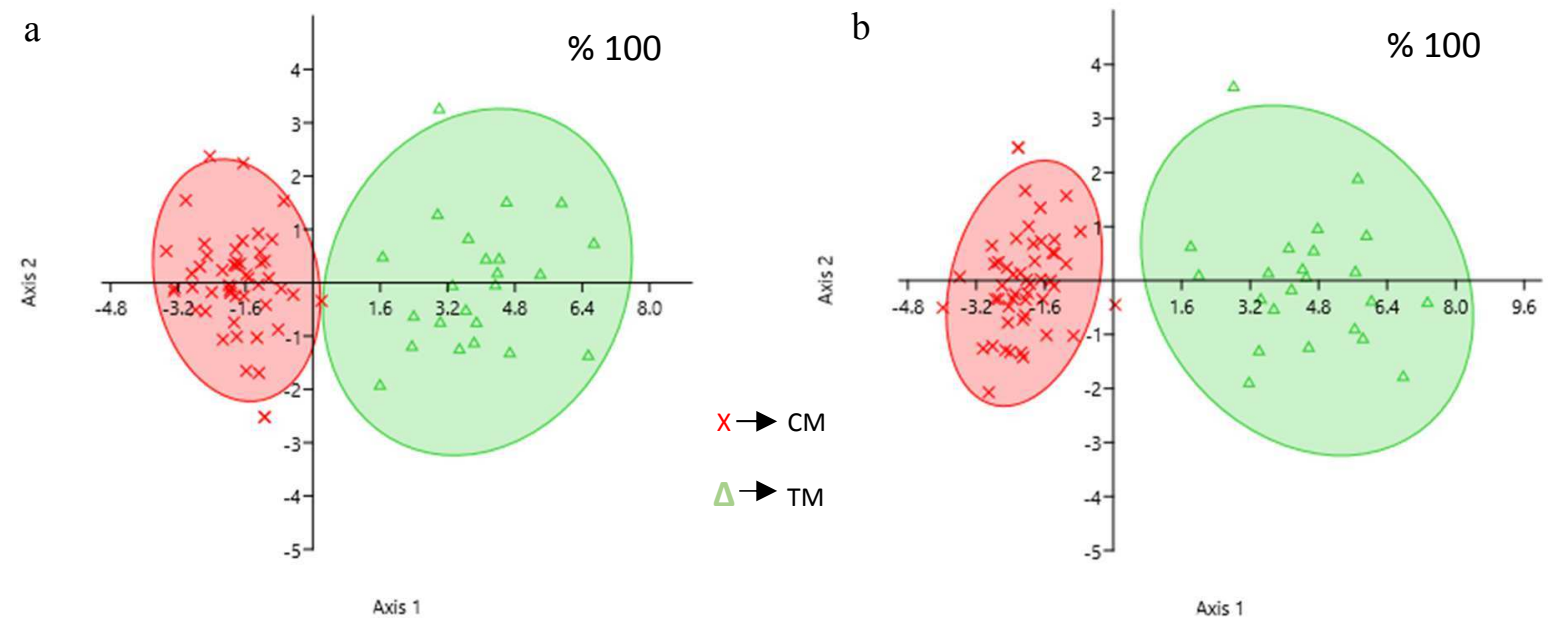

Figure 15. Discriminant analysis of measurements of the cut marks and the tooth marks a) before tumbling b) after tumbling. CM represents cut mark and TM represents tooth mark. 


\section{CHAPTER 5}

\section{DISCUSSION}

\subsection{Bone surface morphology}

It is evident from these tumbling experiments that fluvial abrasion can affect bone surface morphology. Bone surfaces showed evidence of smoothing and polishing after tumbling. Smoothing and polishing on bone surfaces were also observed in the studies of GaudzinskiWindheuser et al. (2010) and Griffith et al. (2016). In the present study, it was observed that the abrasion rate of the medullary cavities of bones was minimal. This is consistent with the observations of Shipman and Rose (1988), who found that concave surfaces were abraded less than convex surfaces. In these experiments, it was observed that sand became compacted in the medullary cavities of the bones during tumbling, and this may have protected these surfaces from abrasion.

After tumbling, depressions and parallel straight incisions were apparent on the surfaces of some cattle bones. Depressions only occurred on cattle bones that were tumbled together. This suggests that the depressions on the bone surfaces may be the result of the bones impacting one another during tumbling. The parallel straight incisions formed only on the surfaces of two cattle bones that were tumbled together. For this reason, it was presumed that these incisions resulted from the frequent friction of the bones against each other. The depressions can be easily distinguished from the abraded and unabraded tooth marks and cut marks because they are much wider and have smoother surfaces. Some of the incisions superficially resemble tooth scratches because they are U-shaped in cross section. However, they are shallower than abraded and unabraded tooth scratches observed in this study. These findings suggest that the interaction of 
bones with each other during transport in fluvial environments cannot be expected to produce marks that can be mistaken for cut marks and tooth marks. However, the interaction between bones and other objects, such as rocks, during transport was not tested and the effect of collisions between bones and other objects remains unknown.

\subsection{Changes in cut mark morphology}

The results of the qualitative analysis on cut marks are largely inconsistent with previous research (Shipman and Rose, 1983, 1988; Gaudzinski-Windheuser et al., 2010) in that the level of the abrasion on cut marks is comparatively lower in the present study. Shipman and Rose (1983, 1988) presented that the slicing marks created on clean animal bones lost all defining features after five hours of tumbling (using a geologic tumbling barrel). They (Shipman and Rose, 1988) asserted that "hydraulically transported bones cannot be expected to show cut marks that can be identified on the basis of SEM inspection" (Shipman and Rose, 1988, p. 320). Additionally, GaudzinskiWindheuser et al. (2010) found that most cut marks on cattle bones were altered or completely eroded after as little as 3 to 6 hours of abrasion. However, the results of the present study indicate that most cut marks on bones that were tumbled for much longer periods of time (152 hours) were still visible and 65.3 percent of the cut marks still preserved at least one diagnostic feature.

The results of the present study also indicate that shoulders associated with stone tool cut marks can be affected by fluvial abrasion. Shoulders were initially present on 30 of 49 cut marks. After tumbling, the shoulders of 19 of these cut marks were nearly or completely dissolved and only 11 cut marks preserved these forms. These results suggest that shoulders may be destroyed by fluvial abrasion, but not in every instance.

Quantitative analyses of cut mark micromorphology show significant changes resulted from tumbling. Variables measured from the 3-D studiables show significant changes to surface 
area, maximum depth, mean depth, maximum length and maximum width of the cut marks, while measurements from 2-D profiles show changes in the maximum depth, maximum width, roughness, angle, and radius of the cut marks. While the surface area, volume, maximum width, angle, and radius values increased after tumbling, maximum depth, mean depth, maximum length, area, and roughness decreased. These results indicate that the cut marks became wider, shorter, and shallower, which as a result show that fluvial abrasion has potential to affect cut mark morphology.

\subsection{Changes in tooth mark morphology}

Both the qualitative and quantitative analyses show that morphology of tooth marks was only slightly affected by tumbling. Only 21.7 percent of the tooth marks lost one diagnostic feature (crushed inner surface), which reduced the identifiability of the tooth marks. However, unlike cut marks 100 percent of tooth marks maintained at least one diagnostic characteristic. Measurements taken from tooth mark parameters show that only maximum depth values of the tooth marks measured from the deepest profiles changed significantly after abrasion. As explained before, the locations of the deepest point and central point on most of the marks changed after tumbling. However, since the location of the deepest points changed after tumbling significant alterations in maximum depth taken from the deepest profiles is not unexpected. Measurements from the deepest profiles show both increases and decreases in maximum depth after tumbling.

\subsection{Cut mark vs. tooth mark}

Qualitative analyses of cut and tooth marks show that the cut marks were more abraded than the tooth marks and became differentially less identifiable when compared with tooth marks. The greater effect of abrasion on cut marks suggests that frequencies of cut marks in fluviallydeposited fossil assemblages may be underestimated relative to carnivore tooth marks. This would 
likely result in inaccurate assessments of the relative contributions of hominins and carnivores to archaeological sites when frequencies of bone surface modifications are compared with modern feeding trace models based on the incidences of cut-, tooth-, and percussion-marked long bones (Blumenschine, 1988, 1995; Capaldo, 1995; Selvaggio, 1998; Pante et al., 2012; Pante, 2013). While Pante and Blumenschine (2010) found that the incidences of cut-, tooth-, and percussionmarked long bones did not differ between hydraulically transported and non-transported bones, they did not test the effect of abrasion on the differential preservation of marks and as a result likely underestimated the effect of fluvial processes on these important measures of hominin and carnivore feeding behavior.

Quantitative analysis of tooth and cut marks also show abrasion has a greater effect on cut marks than tooth marks. However, unlike the qualitative analyses it is still possible to distinguish between these marks after tumbling with $100 \%$ accuracy using multivariate analysis of the measured parameters. These results bolster the need for quantitative methods in the identification of tooth and cut mark on fossil bones, particularly when they are recovered in fluvial environments.

\subsection{Different level of abrasion between cut marks and tooth marks}

The greater effects of abrasion on cut marks can in part be explained by differences in their depth values of tooth and cut marks before tumbling. The mean of the mean depth values for the cut marks was much lower $(37 \mu \mathrm{m})$ than those of the tooth marks $(71 \mu \mathrm{m})$ before tumbling. This is also supported by a comparison of the cut marks that were made on cattle bones against those made on deer bones. The cut marks on the deer bones were deeper (the mean of the mean depth is $39.7 \mu \mathrm{m}$ ) than the cut marks on the cattle bones (the mean of the mean depth is $33.7 \mu \mathrm{m}$ ). Quantitative comparisons of the morphological changes that result after tumbling show that the deeper cut marks on deer bone are also less affected by fluvial abrasion. For example, the following 
variables changed for cut marks on cattle bones, but not deer after tumbling: maximum depth and maximum length (3-D measurements). Overall these findings indicate that shallower marks are more susceptible to quantitative morphological changes than deeper marks and cut marks are less likely to remain identifiable in fluvial environments.

\subsection{Variations in abrasion}

Several studies have shown that the type of sediment, sediment grain size, sediment grain morphology, bone condition and proportion of sediment/water can affect the abrasion rate of bone (Shipman and Rose, 1988; Fernandez-Jalvo and Andrews, 2003; Gaudzinski-Windheuser et al., 2010; Griffith et al., 2016). This suggests that studies conducted under different conditions can yield different results. Therefore, the inconsistency between the results of the present study and the other studies (Shipman and Rose, 1983, 1988; Gaudzinski-Windheuser et al., 2010) could stem from using different types and proportions of materials. Shipman and Rose $(1983,1988)$ used different types of sediment such as loess, fine sand, mixed sand, coarse sand, and gravel. These sediment types could cause different degrees of abrasion on bone surfaces (Fernandez-Jalvo and Andrews, 2003; Griffith et al., 2016). Also, they (Shipman and Rose, 1983, 1988) did not use water in every tumbling experiment, which could increase the level of abrasion on bone (GaudzinskiWindheuser et al., 2010; Thompson et al., 2011). In the tumbling experiments of GaudzinskiWindheuser et al. $(2010)$, the ratio of sand to water $(0.014,0.007)$ is much lower than the ratio used in the present study (0.4286). This could have resulted in the lower abrasion rates observed here, as Gaudzinski-Windheuser et al. (2010) claimed that an increase in the amount of water caused a decrease in the level of abrasion. Griffith et al. (2016) found that gravels caused higher abrasion on fresh bones than fine and coarse sands. Consequently, the greater level of abrasion on the cut marks in these studies could result from using different type of sediment and exclusion of 
water. Therefore, the experimental conditions used in this study should be considered when interpreting the results. Bones are carried in fluvial channels that contain various types of sediment and have different water flow velocities (Behrensmeyer, 1988). Therefore, we should expect the effect of transport in fluvial channels on bones and bone surface modifications to be highly variable.

\subsection{The limitations of the study}

Shipman and Rose (1988) and Thompson et al. (2011) acknowledged the disadvantages of using rock tumbler for abrasion experiments. Rock tumblers cannot accurately create all conditions of natural fluvial processes (Shipman and Rose, 1988; Thompson et al., 2011). In the present study, the continual contact of the bones with each other during 152 hours in the tumbler may have resulted in the formation of the depressions and the parallel straight lines on the bone surfaces. The conditions that created these marks on the bones may not accurately reflect natural fluvial environments. It has also been argued that a tumbler causes sediment to strike bone surfaces more than would occur in a fluvial environment (Shipman and Rose, 1988), which would accelerate rates of abrasion. Behrensmeyer (1982) demonstrated that the degree of abrasion is not directly related to the distance that bones were transported, but to the level of interaction between the bones and sediment during transport (Behrensmeyer, 1982). In the present research, hours of tumbling were not translated into distance that the bones would be transported in natural settings because the tumbler would give rise to more rapid abrasion of bone surfaces than natural fluvial abrasion (Shipman and Rose, 1988). On the other hand, "it does offer substantial advantages in terms of simplicity, replicability, control over variables, and a good return in knowledge for effort expended" (Shipman and Rose, 1988, p. 318). It is for these reasons a tumbler was chosen for this study. 
The methodologies that have been applied provide detailed qualitative and quantitative results for assessing the effect of fluvial abrasion on bone surface modification, but also have some limitations. It is difficult to take cross-sectional profiles from the exact same locations on the marks before and after tumbling. As a result, assessments of modifications to the 2-D profiles may be inaccurate. The procedure implemented (creating "V" and "O" symbols around the marks, taking the four profiles from four different locations after tumbling) helped minimize the impact of this problem. Also, it was occasionally difficult outline the marks to collect the 3-D measurements, because bone surfaces are not completely smooth and have a lot of hollows and ridges that can obscure mark borders. The borders of these parts of the marks after tumbling were estimated by looking at the location of the hollows on the 2-D studiables created before tumbling. Thus, the borders of the marks and the hollows were occasionally inferred.

Pante et al. (2017) tested the precision of this 3-D quantitative method for measuring cut and tooth marks and the measurements were taken by three different analysts. Pante et al. (2017) found that profile measurements indicated higher error than 3-D measurements, suggesting that 3D measurements were more reliable in comparison to 2-D measurements. They claim that the higher error in profile measurements could result from the difficulty of taking the cross-sectional profiles from the exact same locations in separate scans (Pante et al., 2017). Since the same issue occurred in the present study, the 3-D measurements are also likely to be more reliable than the profile measurements in the present study. For the cut marks, most of the variables in both 3-D and profile measurements show significant change after tumbling. For the tooth marks, only the maximum depth values from the deepest profiles changed significantly after tumbling while the maximum depth values from 3-D measurements do not indicate significant differences. 
Another limitation resulted from a few tooth marks that became larger and did not fit the scanned areas after tumbling. The borders of these marks were set as large as possible after tumbling. However, this problem could be remedied by scanning a larger area before tumbling in future studies. 


\section{CHAPTER 6}

\section{CONCLUSION}

Vertebrate fossils are often preserved in fluvial environments (Behrensmeyer, 1988) and as a result, have been exposed to sediment abrasion (Shipman and Rose, 1988). Therefore, it is vital to understand the effects of fluvial abrasion on bone surface modifications to make inferences about hominin behavior and feeding ecology from these feeding traces on fossils recovered from fluvial environments (Pante, 2013). Despite these implications, the effect of fluvial abrasion on stone tool cut marks was previously investigated by only a few studies (Shipman and Rose, 1983, 1988; Gaudzinski-Windheuser et al., 2010) while the effect on mammalian carnivore tooth marks was completely unknown. Additionally, no previous experimental studies produced detailed quantitative information from these marks before and after tumbling. Therefore, this study is not only the first to identify the differential effect of fluvial abrasion on cut and tooth marks, it is also the first to quantify these differences using high-resolution 3-D data.

In the present study, the qualitative and quantitative analyses indicated that fluvial abrasion has the potential to affect cut mark morphology. While the degree of abrasion was high enough to remove internal striations and to reduce the identifiability of cut marks, most of the cut marks retained at least one diagnostic feature. The quantitative analyses indicated that sediment abrasion resulting from hydraulic abrasion significantly altered the micromorphology of cut marks. Specifically, the cut marks became wider, shorter, and shallower after abrasion.

The study also shows that the carnivore tooth marks were affected less than cut marks by abrasion. It is thought that this different level of abrasion resulted from the higher depth values of tooth marks in comparison to those of cut marks. One hundred percent of the tooth marks preserved 
at least one of their qualitative diagnostic features, while almost all quantitative measures of the micromorphology of the tooth marks were not altered significantly after tumbling. The only significantly altered measure was maximum depth of the 2-D profiles.

The differential effect of fluvial abrasion on cut marks and tooth marks has implications for inferences about hominin and carnivore behavior that are based on the assemblage-wide frequencies of cut-, tooth-, and percussion-marked long bones. The frequencies of bone surface modifications in fossil assemblages have been used to infer the relative order of hominin and carnivore access to carcasses and the type and amount of foods consumed by hominins at archaeological sites (Blumenschine, 1995; Selvaggio, 1998; Pante et al., 2012; Pante, 2013). This study has shown that application of these models in fluvial environments should consider that frequencies of cut marks may be underestimated due to the effect of hydraulic abrasion.

This study also demonstrates the importance of 3-D quantitative methods for the identification of the bone surface modifications, particularly when fossils are found in fluvial environments. Multivariate analysis of the measured parameters allows discrimination between cut marks and tooth marks with $100 \%$ accuracy before and after abrasion. This level of accuracy and precision cannot be obtained with qualitative methods.

Future research on the effects of fluvial abrasion on bone surface modifications should be conducted under different experimental conditions. Researchers should use different types of sediment and bone and different proportions of sediment/water in their abrasion experiments to produce more comprehensive interpretations about the effects of fluvial abrasion on the bone surface modifications. Examining the effects of fluvial abrasion on cut mark and tooth mark morphology remains essential necessary if we are to make reliable inferences about the feeding ecology and behavior of hominins and mammalian carnivores. 


\section{REFERENCES CITED}

Behrensmeyer, A. K. (1978). Taphonomic and ecologic information from bone weathering. Paleobiology, 4(02), 150-162.

Behrensmeyer, A. K. (1982). Time resolution in fluvial vertebrate assemblages. Paleobiology, 8(03), 211-227.

Behrensmeyer, A. K. (1988). Vertebrate preservation in fluvial channels. Palaeogeography, Palaeoclimatology, Palaeoecology, 63(1-3), 183-199.

Bello, S. M., \& Soligo, C. (2008). A new method for the quantitative analysis of cutmark micromorphology. Journal of Archaeological Science, 35(6), 1542-1552.

Bello, S. M. (2011). New results from the examination of cut-marks using three-dimensional imaging. In The Ancient Human Occupation of Britain, Amsterdam: The Netherlands (pp. 249262).

Binford, L. R. (1981). Bones: Ancient Men and Modern Myths.

Binford, L. R. (1981). Middle-range research and the role of actualistic studies. Bones: Ancient Men and Modern Myth. Academic Press, New York.

Blumenschine, R. J. (1988). An experimental model of the timing of hominid and carnivore influence on archaeological bone assemblages. Journal of Archaeological Science, 15(5), 483502 .

Blumenschine, R. J., \& Selvaggio, M. M. (1988). Percussion marks on bone surfaces as a new diagnostic of hominid behaviour. Nature, 333(6175), 763-765.

Blumenschine, R. J. (1995). Percussion marks, tooth marks, and experimental determinations of the timing of hominid and carnivore access to long bones at FLK Zinjanthropus, Olduvai Gorge, Tanzania. Journal of Human Evolution, 29(1), 21-51.

Blumenschine, R. J., Marean, C. W., \& Capaldo, S. D. (1996). Blind tests of inter-analyst correspondence and accuracy in the identification of cut marks, percussion marks, and carnivore tooth marks on bone surfaces. Journal of Archaeological Science, 23(4), 493-507.

Bunn, H. T. (1981). Archaeological evidence for meat-eating by Plio-Pleistocene hominids from Koobi Fora and Olduvai Gorge.

Boschin, F., \& Crezzini, J. (2012). Morphometrical analysis on cut marks using a 3D digital microscope. International Journal of Osteoarchaeology, 22(5), 549-562.

Brain, C. K. (1981). The hunters or the hunted?. University of Chicago Press.

Capaldo, S. D., \& Blumenschine, R. J. (1994). A quantitative diagnosis of notches made by hammerstone percussion and carnivore gnawing on bovid long bones. American Antiquity, 724748. 
Capaldo, S. D. (1995). Inferring hominid and carnivore behavior from dual-patterned archaeofaunal assemblages. Rutgers University.

Domínguez-Rodrigo, M., De Juana, S., Galán, A. B., \& Rodríguez, M. (2009). A new protocol to differentiate trampling marks from butchery cut marks. Journal of Archaeological Science, 36(12), 2643-2654.

Fisher, J. W. (1995). Bone surface modifications in zooarchaeology. Journal of Archaeological method and theory, 2(1), 7-68.

Gaudzinski-Windheuser, S., Kindler, L., Rabinovich, R., \& Goren-Inbar, N. (2010). Testing heterogeneity in faunal assemblages from archaeological sites. Tumbling and trampling experiments at the early-Middle Pleistocene site of Gesher Benot Ya'aqov (Israel). Journal of Archaeological Science, 37(12), 3170-3190.

Gifford, D. P. (1981). Taphonomy and paleoecology: a critical review of archaeology's sister disciplines. Advances in archaeological method and theory, 4, 365-438.

Gilbert, W. H., \& Richards, G. D. (2000). Digital imaging of bone and tooth modification. The Anatomical Record, 261(6), 237-246.

Greenfield, H. J. (1999). The origins of metallurgy: distinguishing stone from metal cut-marks on bones from archaeological sites. Journal of Archaeological Science, 26(7), 797-808.

Griffith, S. J., Thompson, C. E. L., Thompson, T. J. U., \& Gowland, R. L. (2016). Experimental abrasion of water submerged bone: The influence of bombardment by different sediment classes on microabrasion rate. Journal of Archaeological Science: Reports, 10, 15-29.

Hammer, Ø., Harper, D. A. T., \& Ryan, P. D. (2001). Paleontological Statistics Software: Package for Education and Data Analysis. Palaeontologia Electronica.

Haynes, G. (1980). Evidence of carnivore gnawing on Pleistocene and Recent mammalian bones. Paleobiology, 6(03), 341-351.

Haynes, G. (1983). Frequencies of spiral and green-bone fractures on ungulate limb bones in modern surface assemblages. American antiquity, 102-114.

Jalvo, Y. F., \& Andrews P. (2003). Experimental effects of water abrasion on bone fragments. Journal of taphonomy, 1(3), 145-161.

Krumbein, W. C., \& Sloss, L. L. (1951). Stratigraphy and sedimentation (Vol. 71, No. 5, p. 401). LWW.

Lyman, R. L. (1987). Archaeofaunas and butchery studies: a taphonomic perspective. Advances in archaeological method and theory, 10, 249-337.

Merritt, S. R. (2012). Factors affecting Early Stone Age cut mark cross-sectional size: implications from actualistic butchery trials. Journal of Archaeological Science, 39(9), 2984-2994.

Noe-Nygaard, N. (1989). Man-made trace fossils on bones. Human Evolution, 4(6), 461-491. 
Oliver, J. S. (1994). Estimates of hominid and carnivore involvement in the FLK Zinjanthropus fossil assemblage: some socioecological implications. Journal of Human Evolution, 27(1-3), 267294.

Olsen, S. L., \& Shipman, P. (1988). Surface modification on bone: trampling versus butchery. Journal of Archaeological Science, 15(5), 535-553.

Pante, M. C., \& Blumenschine, R. J. (2010). Fluvial transport of bovid long bones fragmented by the feeding activities of hominins and carnivores. Journal of Archaeological Science, 37(4), 846854.

Pante, M. C., Blumenschine, R. J., Capaldo, S. D., \& Scott, R. S. (2012). Validation of bone surface modification models for inferring fossil hominin and carnivore feeding interactions, with reapplication to FLK 22, Olduvai Gorge, Tanzania. Journal of human evolution, 63(2), 395-407.

Pante, M. C. (2013). The larger mammal fossil assemblage from JK2, Bed III, Olduvai Gorge, Tanzania: implications for the feeding behavior of Homo erectus. Journal of human evolution, 64(1), 68-82.

Pante, M. C., Muttart, M. V., Keevil, T. L., Blumenschine, R. J., Njau, J. K., \& Merritt, S. R. (2017). A new high-resolution 3-D quantitative method for identifying bone surface modifications with implications for the Early Stone Age archaeological record.Journal of Human Evolution, 102, 1-11.

Pickering, T. R., Dominguez-Rodrigo, M., Egeland, C. P., \& Brain, C. K. (2005). The contribution of limb bone fracture patterns to reconstructing early hominid behaviour at Swartkrans Cave (South Africa): archaeological application of a new analytical method. International Journal of Osteoarchaeology, 15(4), 247.

Pobiner, B. L., Rogers, M. J., Monahan, C. M., \& Harris, J. W. (2008). New evidence for hominin carcass processing strategies at 1.5 Ma, Koobi Fora, Kenya. Journal of Human Evolution, 55(1), 103-130.

Potts, R., \& Shipman, P. (1981). Cutmarks made by stone tools on bones from Olduvai Gorge, Tanzania. Nature, 291(5816), 577-580.

Powers, M. C. (1953). A new roundness scale for sedimentary particles. Journal of Sedimentary Research, 23(2).

Selvaggio, M. M. (1994). Carnivore tooth marks and stone tool butchery marks on scavenged bones: archaeological implications. Journal of Human Evolution, 27(1), 215-228.

Selvaggio, M. M. (1998). Evidence for a Three-Stage Sequence of Hominid and Carnivore Involvement with Long Bones at FLK Zinjanthropus, Olduvai Gorge, Tanzania. Journal of Archaeological Science, 25(3), 191-202.

Shipman, P., \& Rose, J. (1983). Early hominid hunting, butchering, and carcass-processing behaviors: approaches to the fossil record. Journal of anthropological Archaeology, 2(1), 57-98.

Shipman, P., \& Rose, J. J. (1988). Bone tools: an experimental approach. In Scanning electron microscopy in archaeology (pp. 303-335). British Archaeological Reports. 
Sutcliffe, A. J. (1970). Spotted hyaena: crusher, gnawer, digester and collector of bones. Nature, 227(5263), 1110-1113.

Thompson, C. E. L., Ball, S., Thompson, T. J. U., \& Gowland, R. (2011). The abrasion of modern and archaeological bones by mobile sediments: the importance of transport modes. Journal of Archaeological Science, 38(4), 784-793.

Walker, P. L., \& Long, J. C. (1977). An experimental study of the morphological characteristics of tool marks. American antiquity, 605-616.

Wentworth, C. K. (1932). The terminology of coarse sediments (with notes by PGH Boswell): Nat. Research Council Comm. on Sedimentation Rept, 1934, 225-246. 